Portland State University

PDXScholar

7-18-1979

\title{
A Comparison of Dramatic Storytelling and Puppet Storytelling as a Means of Teaching Selected Nutritional Concepts
}

Edith M. Martin

Portland State University

Follow this and additional works at: https://pdxscholar.library.pdx.edu/open_access_etds

Part of the Education Commons, Nutrition Commons, and the Speech and Hearing Science Commons Let us know how access to this document benefits you.

Recommended Citation

Martin, Edith M., "A Comparison of Dramatic Storytelling and Puppet Storytelling as a Means of Teaching Selected Nutritional Concepts" (1979). Dissertations and Theses. Paper 2905.

https://doi.org/10.15760/etd.2901

This Thesis is brought to you for free and open access. It has been accepted for inclusion in Dissertations and Theses by an authorized administrator of PDXScholar. Please contact us if we can make this document more accessible: pdxscholar@pdx.edu. 
AN ABSTRACT OF THE THESIS OF Edith M. Martin for the Master of Science in Speech Communication presented July 18, 1979.

Title: A Comparison of Dramatic Storytelling and Puppet Storytelling as a Means of Teaching Selected Nutritional Concepts.

APPROVED BY MEMBERS OF THE THESIS COMMITTEE:
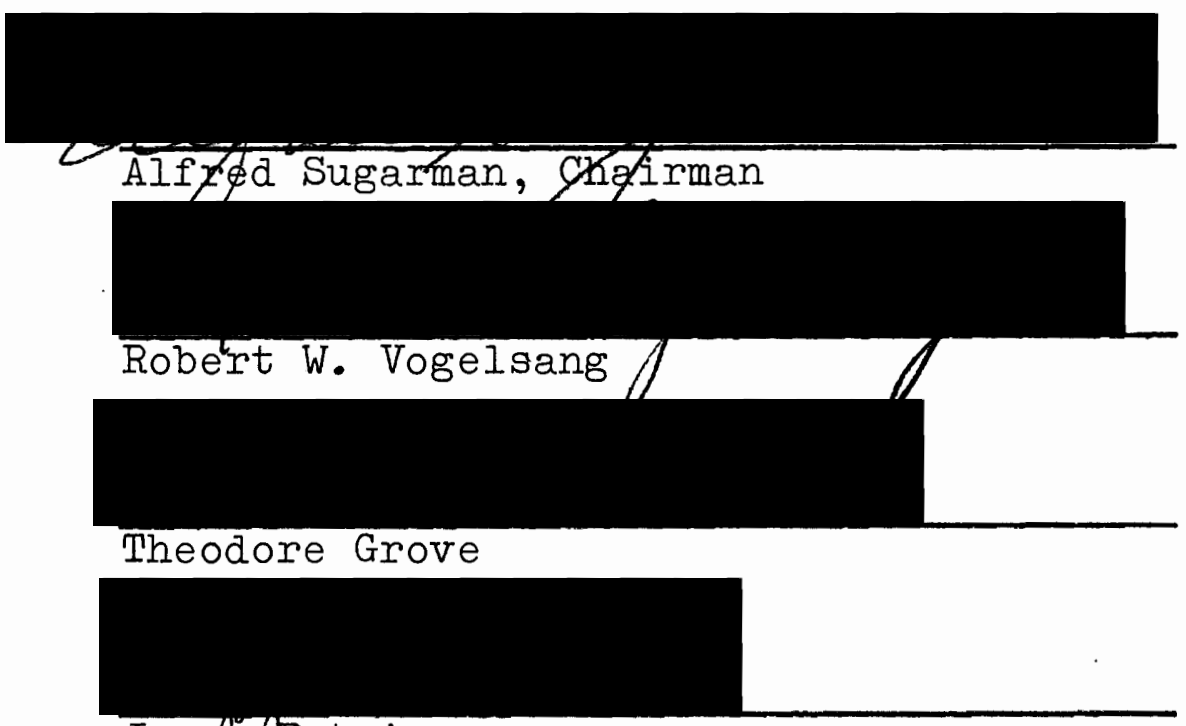

Joydl Upetrie

The art of puppetry began hundreds of years ago, but it was not until the 1970's that puppetry made a noticeable impact in the United States. Much anecdotal information exists to support the claim that puppetry is an effective educational medium, but little empirical data exists in the field.

The present study investigated the basic question: Will preschool, kindergarten, and first grade students have 
a greater increase in knowledge of selected nutritional concepts as a result of viewing a puppet story than a similar composite will have when the same material is presented via dramatic storytelling?

Secondary questions were also asked which will be enumerated in the hypotheses.

A pretest/posttest design was utilized. The students' increase in knowledge was assessed through investigatordesigned pencil/paper and interview tests. Treatment was the same for the experimental and the control groups with the exception of the one variable, the method of storytelling.

The subjects were 154 preschool, kindergarten, and first grade students at the Helen Gordon Center, the Pixie Day Nursery, and Lynch Park and Lynch Plaza Elementary schools.

The study tested four hypotheses and the findings are as follows:

Null Hypothesis 1: There will be no significant difference in increase of knowledge of selected nutritional concepts for preschool, kindergarten, and first grade students when puppets are used as the instructional medium than when dramatic storytelling is used as the instructional medium. 
In the experimental group, the students had a mean change score of $18.53 \%$. This was $11.58 \%$ higher than the control group's mean change score of $7.95 \%$. Therefore, this hypothesis was rejected.

Null Hypothesis 2: There will be no significant difference among the mean change scores of preschool, kindergarten, and first grade students in this study.

Preschooler's had a mean change score of $27.89 \%$; kindergarteners, 16.23\%; and first graders, 11.35\%. Therefore, this hypothesis was rejected.

Null Hypothesis 3: There will be no significant difference in the mean change scores among preschool, kindergarten, and first grade students as a result of treatment (puppet storytelling or dramatic storytelling) in this study.

As in the data for hypothesis 2, preschoolers had the highest change scores of $39.5 \%$ in the experimental group; and $15.39 \%$ in the control group. Kindergarteners were next with mean change scores of $19.32 \%$ in the experimental group, and $8.62 \%$ in the control group. First graders had the least gain, $13.78 \%$ in the experimental group, and $1.37 \%$ in the control group.

These statistics reject null hypothesis 3 and add further rejection to null hypotheses 1 and 2 . 
The parallel pattern of the statistics enumerated for null hypotheses 3 and 4 intrigued this researcher. An analysis of early childhood psychology literature revealed that the younger the child (4-6), the greater his ability to enter the realm of fantasy. This researcher believes that this could have been an important factor in the change score pattern of Preschoolers > Kindergarteners > First graders, but more research is needed to confirm that supposition.

Null Hypothesis 4: There will be no significant difference in the mean change scores registered by male and female subjects.

The differences in change scores of male and female subjects in this study were so slight, that the researcher contributes them to chance and agrees with the null hypothesis.

With this one exception all of the hypotheses were rejected. They answered the basic research question with a resounding "yes," students will have a greater increase in knowledge of selected nutritional concepts as a result of viewing a puppet story than a similar composite of students will have when the same material is presented via dramatic storytelling. 
A COMPARISON OF DRAMATIC STORYTELLING. AND PUPPET STORYTELLING AS A MEANS OF TEACHING SELECTED NUTRITIONAL CONCEPTS

by

EDITH M. MARTIN

A thesis submitted in partial fulfillment of the requirements for the degree of

\author{
MASTER OF SCIENCE \\ in \\ SPEECH COMMUNICATION
}

Portland State University

1979 
TO THE OFFICE OF GRADUATE STUDIES AND RESEARCH:

The members of the Committee approve the thesis of Edith M. Martin presented July 18, 1979.

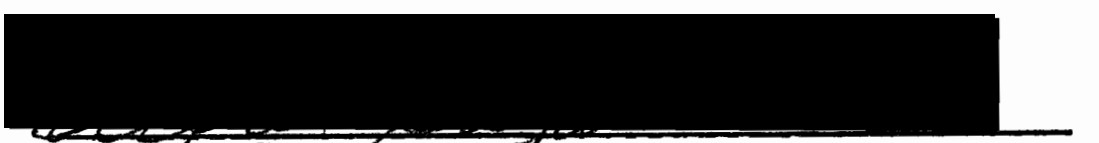

Alfyed Sugarman, Chairman

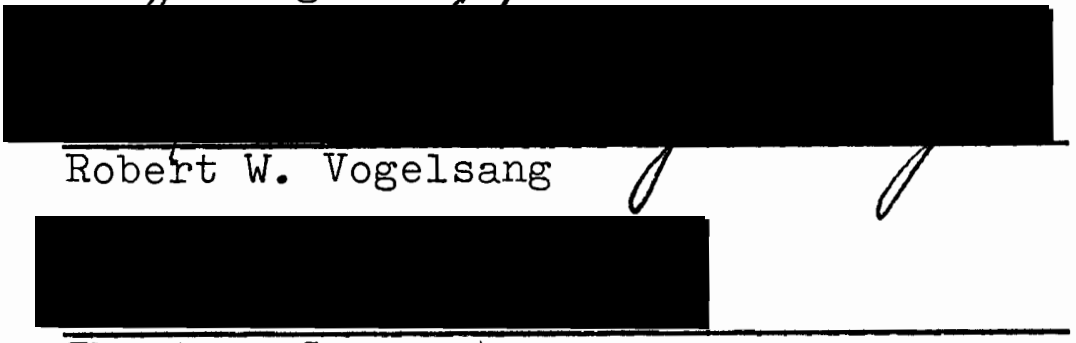

Theodore Grove

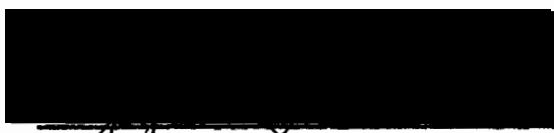

Jotycle Petrie

APPROVED :

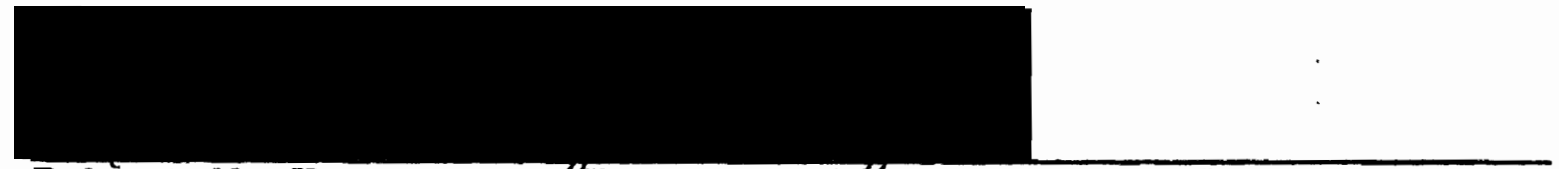

Robert W. Vogelsang, Chairman, D\&partment of Speech Communication

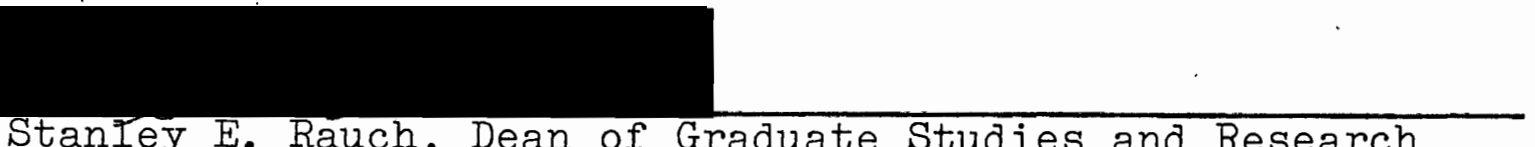

Stanley E. Rauch, Dean of Graduate Studies and Research 


\section{ACKNOWLEDGMENTS}

In March of 1978, after having taught speech and drama for twenty years, I decided to once again enter the ranks of the student. Having made that decision, I enrolled in a class entitled, "Puppetry for Clinic and Classroom" which was taught by Professor Robert Vogelsang. That was my first exposure to puppetry and my inspiration.

Seeing the great potential that this medium held, I began investigating and experimenting. As I continued my courses in Speech Communication, the opportunity arose to participate in a project involving the teaching of nutrition through puppets. That proved to be the inspiration and the opportunity for this thesis and I would like to thank Professor Robert Vogelsang for that inspiration and opportunity.

I would also like to express my appreciation to my daughter, Deborah, who spent many hours typing draft copies from my scribbly notes, and to Nancy Steffan, who also burned the midnight oil to complete the typing of my draft.

The members of my committee also deserve special thanks. Professor Robert Vogelsang was most helpful and encouraging. Professor Alfred Sugarman was meticulous in 
his attention to detail, and Theodore Grove provided the statistical guidance.

I would also like to thank my good friend James Dixson who came to my rescue and who provided the statistical interpretive assistance necessary to complete this project.

To these friends and all others, especially my family, who offered reassurance, condolences, and a sympathetic ear, I say, "Thanks for being a friend. We made it!" 
TABLE OF CONTENTS

PAGE

ACKNOWLEDGMENTS . . . . . . . . . . .

LIST OF TABLES

viii

IIST OF FIGURES ............. ix

CHAPTER

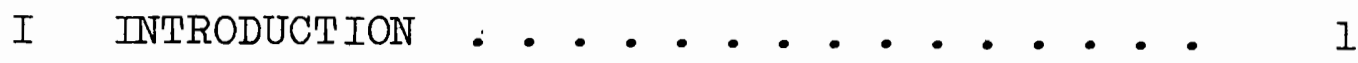

Purpose . . . . . . . . 2

Definitions ........ . 2

Justification ......... . 2 2

Research Questions ....... 3

II REVIEW OF THE LITERATURE ........ 5

Origin of Puppetry ....... 5

Puppetry and Religion...... 7

Puppetry and Education ...... 9

Puppetry in Early Childhood

Education

Puppets in Therapy

Puppetry and Speech Therapy

Puppets and the Physically.

Handicapped

Puppetry and the Mentally

Handicapped

Puppets and Language Teaching

Puppets and Language Arts

Puppetry and Social Studies

Puppetry and Mathematics 
Television's Influence on

Puppetry ....... . . 24

Puppetry and Politics . . . . . 25

Empirical Data Versus Anecdotalism • • 25

Empirical Studies . . . . . . 26

Summary • • • • • • • • • . 28

II METHODS AND PROCEDURES . • • . . • . 34

Hypotheses . . . . . . . . 34

Definitions . . . . . . . 35

Design • • • • • • • • • • • • 35

Subjects . . . . . . . . 36

The Pretest ......... 38

Pretest for Lynch Plaza and Iynch

Park Elementary Schools

Pretest for Helen Gordon Center and Pixie Day Nursery

Preparation of Story Script . . . . 43

The Puppets . . . . . . . . 44

Properties and Theater....... . 45

Presentation of Puppet Storytelling • . 46

Presentation of Dramatic Storytelling • 47

The Posttest . . . . . . . 48

Data Analysis ........ . 49

IV RESULTS AND DISCUSSION . . . . . . 52

Results •. •. •. •. •. • 53

Discussion . . . . . . . 60 
V SUMMARY AND IMPIICATIONS • • • • • • 75

Summary . •. •. •. •. • . 75

Implications . . . . . . . 78

BIBLIOGRAPHY

APPENDIX

A Pretest Objectives, Pretest, and Posttest .......... . 86

B Script for Puppet Storytelling, and Script for Dramatic Storytelling ... . . 104

C Photographs of Puppets and Props . . . . 119

$D$ List of All Pretest, Posttest, and Change Scores . . . . . . . 127 
IIST OF TABLES

TABLE

PAGE

I Comparison of Experimental and Control

Groups' Mean Scores . . . . . . 54

II Comparisons of Experimental and Control

Groups • • • • • . . • . . 55

II Comparison of Mean Pretest, Posttest, and

Change Scores by Grade Level . . . . 57

IV t-Test Comparisons of Experimental and

Control Groups' Change Scores . . . . 58

$\mathrm{V}$ Comparison of Mean Pretest, Posttest, and

Change scores by Sex . . . . . . . 59 
IIST OF FIGURES

FIGURE

PAGE

1. Jody and Granny Goody . . . . . . . 120

2. Granny Goody .. . . . . . . . . 121

3. Jody . . . . . . . . . . . . 122

4. Backdrop and Props . . . . . . . . . 123

5. Props for Jody's Breakfast . . . . . . 124

6. The Iunch Sack Props . . . . . . . . 125

7. Jody's Iunch Props . . . . . . . . 126 
CHAPTER I

INTRODUCTION

More than a toy,

A. source of joy,

To a child alone, is a puppet.

More than a thing,

An aid in speaking,

To a child in a group, is a puppet.

More than mere levity,

A chance for creativity,

To a child in despair, is a puppet.

More than to cuddle,

For one in a muddle,

To a child everywhere, is a puppet. ${ }^{1}$

In these few lines by May Ostrow, just a few of the many uses of puppetry are introduced. More diverse than painting, sculpture, dance, song, or story, puppetry has something of all of them. It is theater. It is art. It is an extension of human expression. It is a means of education and communication.

A review of the literature indicates that the art of puppetry began hundreds of years ago, but it was not until the 1970's that puppetry made a noticeable impact in the United States. Today puppets perform on television, in theaters, in shopping centers, and at schools. Though traditional entertainment uses continue, the value of puppetry as an educational medium has been discovered. 
Teachers, therapists, youth leaders, environmentalists, and governmental agencies throughout the world use puppets to pass on messages and to develop understandings. As a result, puppetry, in addition to its value as pure entertainment, has become an effective tool for communicating and instructing. Much anecdotal information is available to document this claim, but little empirical data exists to support it.

\section{PURPOSE}

The purpose of this study is to assess the value of puppets as an instructional medium for teaching selected nutritional concepts to preschool, kindergarten, and first grade students, thus adding one bit of empirical data to the field.

\section{DEF INIT IONS}

Selected nutritional concepts are defined as:

(1) "Food gives you energy," (2) "you need energy to do active things," (3) "you are more likely to tire easily when you don't eat your meals," and (4) "you need to eat food from each of the four basic food groups each day."

\section{JUSTIFICAT ION}

This area was chosen first of all because nutrition is of vital importance to everyone. Secondly, it was chosen because schools include these selected nutritional 
concepts in their primary grades' curriculum and need a more interesting way of presenting the concepts. And thirdly, because no empirical data was available in the area of puppetry and nutrition. There was also no comparison of puppet storytelling and dramatic storytelling to be found in the research of the literature.

\section{RESEARCH QUESTIONS}

The essential research question was: Will preschool, kindergarten, and first grade students have a greater increase in knowledge of selected nutritional concepts as a result of viewing a puppet story than a similar composite of students will have when the same material is presented via dramatic storytelling?

Secondary questions were:

1. Will change scores be significantly different among the preschool, kindergarten, and first grade levels?

2. Will treatment (puppet or dramatic storytelling) cause change scores to be significantly different among preschool, kindergarten, and first grade students?

3. Will there be any difference between change scores of male and female subjects in this study? 


$$
\text { Chapter 1--Notes }
$$

$I_{\text {May. B. Ostrow and Debra Taylor, "Why a Puppet," }}$ Puppetry in Compensatory Education (Sanford, Florida: Seminole County Board of Public Instruction, 1973), p. 2. 


\section{CHAPTER II}

\section{REVIEW OF THE LITERATURE}

\section{ORIGIN OF PUPPETRY}

\section{A. R. Philpott in his Dictionary of Puppetry writes:}

"There is no authentic record as to who made the first puppet, when, where, why, out of what material, and with what means of control."l This is not surprising, for to find the origin of puppets, one would have to retrace the path of antiquity, far beyond the days of recorded history. In retracing that path, legends have provided an avenue of speculation.

One such legend states that in about the year 1000 B.C., "Emperor Mu of the Chou Dynasty [reportedly] returned from a visit to Turkestan with materials and artisans for making new things, among them marionettes. "2 Two other Chinese legends, mentioned by Obraztsov in The Chinese Puppet Theatre, give us further accounts of that same period. One is about a puppet master in the tenth century B.C. Who cut open his puppets to prove that they were not live beings and that they were therefore incapable of flirting with the Emperor's wives. The other legend deals with an ingenious effigy made to dance on a city wall. It 
excited the attacking chief's wife to such jealousy that she forced him to call off his attack. ${ }^{3}$ A third legend comes from the mythology of India. It claims that the Adi Nat, or "first puppeteer," was born from the mouth of Brahma, the creator. ${ }^{4}$ Whether one, none, or all are true is open to speculation, but they leave no doubt that puppets did exist as early as the tenth century B.C.

Most historians credit the shadow puppet with being the oldest form of puppetry. A. R. Philpott goes so far as to say, "Historians are agreed that these [shadow puppets] are the oldest form of puppet theatre, but they are uncertain as to whether China or India was the birthplace of the art." 5 This uncertainty can be attributed to the fact that in both China and India, as well as in other areas of Southeast Asia, shadow puppets have performed the sacred stories and brought the gods and heroes to life for centuries. Adding more uncertainty to the actual origin of puppetry, Bil Baird refers to witch doctors who, as long ago as fifteen or twenty thousand years, hinged animal skulls to create articulated masks. He contends that these masks were just an evolutionary step away from the puppet, and that this progression from mask to marionette occurred independently in a number of primitive societies. 6

Robert Bruce Inverarity, anthropologist and puppeteer, supports Baird's claim. He states that the use of puppets controlled by strings was very common among the Northwest 
Coast Indians, 7 and Baird, himself, reports that among the Hopi Indians of the American Southwest ritual puppet dramas were performed with a variety of animal and human figures. He concludes that puppets were used by the American Indian for various religious functions long before the arrival of Columbus. 8

\section{PUPPETRY AND RELIGION}

Whatever the birthplace, as the puppet moves through history and cultures of people throughout the world, it seems first to associate itself with religion. Herodotus, writing in the fifth century B.C., gives us an account of movable figures operated by strings and wires being used in 460 B.C. These puppets, as we might call them, were carried by Egyptian women in religious ceremonies honoring Osiris. 9

Iucian, a Greek, writing 600 years after Herodotus, tells of seeing an oracular Roman god, Jupiter Amon, move. This feat was undoubtedly accomplished by a puppeteer deftly manipulating wires, since the Romans even had a name for the control room, the "adytum," wherein the priest pulled his secret wires. 10

Arnott reinforces the theme that puppetry probably arose from magic and religious rituals when he says:

Then there were the images of the gods, objects of veneration to the people. It would have been a simple and natural step to articulate those figures 
and create an illusion of life. We know of many cases where the priests, whether for pious or venal reasons, caused the statue of the god to

As generations passed, puppetry continued as a religious educational medium. Evidence comes from India, where marionettes were used to dramatize Hindu epjcs and from China and Iapan where they were used to spread Buddhism. However, when the Roman Empire collapsed, the ant of puppetry dropped from sight in Europe. For several hundred years there was no documentary evidence of any sort to give the slightest hint of its fate. The reason for its disappearance might have been because of the early Christians' belief that any kind of show or idolatrous image was abhorrent. So it was not until somewhere between the seventh and ninth centuries that puppetry was again heard of in Europe. By that time it had been put to the service of the growing Christian religion.

The early Christian church, frowning on the vulgarity of live actors, needed some way to elevate the common people to knowledge, so it welcomed the puppet. As a result, puppetry became an important part of European medieval religion and drama. It was the church's vehicle of religion.

By the eleventh century, however, abbots were denouncing puppets as "smacking of idolatry," and by the thirteenth century, even the Pope was speaking against them. 12 
When the puppets were thrown out of the church, it was not because they were not getting their message across, it was because the morality plays had become too theatrical or vulgar. Sylwester writes: "Even though the puppet was banned from the church in 1540 , it continued to present Bible stories outside the church." He states further that during the Middle Ages, puppetry became an important means of teaching Bible stories to "the illiterate laity in Europe," and he adds that puppetry seems to have "been born out of a need for man to illustrate, to influence, and to communicate." 13

\section{PUPPETRY AND EDUCATION}

Born from this need, puppetry continues to fulfill the need. Puppets are being used as an educative medium throughout the world to illustrate concepts, to influence behavior, and to communicate with people of all ages, races, and mental and physical oapabilities. Puppetry's educative value today seems to lie in two modes. whereas in past centuries people were generally observers, today puppetry is equaliy valuable as a participatory activity. One such participatory activity is the use of puppets in early childhood education. 
Puppetry in Early Childhood

Education

Piaget states that play is an indispensable step in a child's cognitive development and that the child's makebelieve activity stimulates his thought. From the age of four to six or seven, the world of fantasy or make-believe is the child's real world, 14 and David $\mathrm{S}$. Rowland states, "With puppets, it is easier to enter the realm of fantasy and imagination." 15

Nancy Quisenberry, Assistant Professor of Early Childhood/Language Arts at Southern Illinois University and Margo Willis, a first grade teacher, write:

We have found that the use of puppets employed as an instrument of learning can work well in early childhood programs. Puppets appear to help the children coordinate their own experiences with language, as well as teaching them to become an attentive audience and to overcome their egocentrism. 16

Quisenberry cites many early childhood educators who contend that children learn through play, and she concludes that puppets can be a learning tool used to stimulate socio-dramatie-ply anditively influence the child's creative, intellectual, and social development. 17

David Currell contends that through the medium of puppetry, children's basic need to act out situations can be completely fulfilled and that this is especially true for the withdrawn personalities. 18

Williams in yet another article on creative drama writes: "Puppets can help a shy child to show ideas, 
because the child is not forced to stand before a group. Ideas can be expressed behind a puppet screen or stage. ${ }^{19}$

\section{Puppets in Therapy}

Young children are not the only ones who can benefit from the use of participatory puppetry. Many times adults can also be helped through that type of communicative activity. In France, Germany, Sweden, Canada, England, and the United States, the educational or communicative use of puppetry which has received the greatest amount of attention has been the use of puppets in communicating with children and adults with varying problems, or as we call them today, the exceptional individuals.

George Latshaw states:

Puppets provide a gentle way of hiding one's self. They are the ultimate disguise, so they are well suited to act as go-betweens in commanication between therapist and patient. They are a tool for liberating the subject and an informative tool for the psychologist on observer.

A. R. Philpott, an instructor in educational puppetry and editor of the Puppet Post, has brought a wealth of information on puppetry and therapy together in a volume which bears the title Puppets and Therapy. Hundreds of situations from around the world are cited in this volume and Philpott has come to the conclusion that there is growing, world-wide interest in using puppetry in therapy, physiotherapy, psychiatry, and rehabilitation, as well as working with the physically handicapped, the emotionally 
disturbed, and the educationally retarded. He found that in Europe as long ago as at least the 1930's puppetry was being used to communicate with patients in various psychiatric clinics. 21

Dr. Simone Marcus of the Ancienne Externe des Hopitaux de Paris writes that the use of glove puppets with which the child could tell the analyst all of his inner conflicts can be traced to Mlle. Madelaine Rambert of Switzerland. She first used dolls, but soon discovered that puppets were more useful, because "they could be handled more easily, were more robust, resisted beating much more and the child could completely disappear behind the guignol's (puppets) personality."22 Marcus concludes that through the puppet method, severe neuroses could be cured in less time than through any athoxwaym

Another case of interest included in Philpott's volume involves Mlle. Jouvent, also of France, who used puppets during and after World War II with war victims, mostly shock cases. She says: "We had practically no failures. All patients were at least much better, few relapsed, and about forty percent were cured completely."23 Puppets in the hands of the maladjusted can communicate many things to a properly trained therapist Joanne Dunhill reports on a study to compare various methods of diagnostic testing; the Bene Anthony Family Relations Test, Raven's Controlled Projection Technique, Kinetic Family 
Drawing Technique, Longdon Doll Technique, and puppets. She investigated three things: "1) What relationship does play with puppets have to traditional methods regarding diagnosis of a particular child? 2) What are the advantages and disadvantages of using puppets? 3) What additional material can be gained by comparisons between the subjects." 24

The above experimenter's investigation involved children at a day unit for maladjusted children. The conclusions of the study, as expressed by the investigator, were, "I ascertained that what I had read about the potential of puppets was actually true. Puppetry was a useful method of diagnosis with children." She further discovered that the child's choice of puppet, the way the child chose to use the stage and the type of stage chosen were important clues to his problems and personality. 25

\section{Puppetry and Speech Therapy}

In the field of speech therapy, puppets have also been used as an aid in diagnosing and correcting spesch difficulties. A specific example comes from the Maywood, New Jersey Public School's speech therapist, Dorothy Delano. She tested children for speech difficulties by having them say hello to a puppet. She states a simple "Hello, Red Samson, can be used to spot poor pronunciation of the sounds e, s, and $r . " 26$

Margaret S. Gordon, speech therapist, in an article entitled "Puppetry in Speech Clinics," reports that most 
speech therapists who have tried puppets are loud in their praise of the help children derive from them, and that success through the use of puppets has been documented by clinicians and training centers throughout the world. She feports further that children with speech disorders that stem from psychological trama find in puppets an outlet for their emotions, and because of this release of tension, speech theraptwis facilitated. The outlet can be in manipulation or construction. She feels that any type of handwork is helpful, but that "if it has a fascinating outcome, such as the creation of a puppet, then the child's interest is at once gained and sustained through the weeks it may take to complete the puppet." 27

According to Gordon, another very important reason why the making of a puppet is of basic help in a speech clinic is because it is a form of self-expression. Many children with speech defects are very handicapped when they try to express themselves in speech, and it is helpful to first encourage methods of self-expression that do not involve the very thing that they find most difficult. Making puppets is one way of doing this. 28

\section{Puppets and the Physically} Handicapped

Puppetry can be adaptable to many categories of exceptionality, but what works with the gifted and talented might not succeed with the mentally retarded and what is 
appropriate for the learning disabled might not work with the physically handicapped. 29

Interesting and beneficial activities have been carried out with the hearing, the visually, and the orthopedically handicapped. In a third grade class at the Texas School for the Deaf, children produced puppets and scenery for Maurice Sendak's Where the Wild Things Are and performed for the entire school. 30 In Chicago, direct presentations to deaf children are made on WTTW, Chicago's educational television station. 31

Evidence that deaf ehidrengain more than selfconfidence from puppetry comes from Violet Philpott, wife of A. R. Philpott and herself a prominent British puppeteer. She tells of how deaf children after viewing a puppet play, without being prompted, wrote stories about characters in the play that they had seen. 32

Ruthmarie Sheehan writes of an experience, with puppetry and blind children. She worked in a camp for blind children and young adults and found the technique of integrating storytelding and pupetry yery useful. The children created the characters of the story in their minds and then made puppotsin of them. When thempuppetswere finished, the children felt each other's creations and introduced their characters. They then performed the story. Sheehan's assessment of the project was that it was very successful. "The puppets proxided an excellent means of expression for 
the children, as well as giving them a rare opportunity to control something outside of themselves." 33

Reich, in "Puppetry--A Language Tool," reports that through a puppet play, the children in a visually handicapped, culturally deprived third grade gained in both language development and social studies. Her comments on the results were:

Since language clarity was essential to the program, the children had a specific reason for desiring to improve their speech. With such effective motivation, plus the reinforcing routine of rehearsal sessions, the children gained facility in their oral language. 34

All children, regardless of handicaps, can usually identify with puppets, but the benefit is so much greater if the puppet has some of the characteristics of the child. In response to this need for puppets with which the orthopedically handicapped could identify, Betty Pollus designed a puppet in a wheelchair. After working with "Wheeler" for two years, she found that there was no limit to the questions a puppet of this type could evoke and the learning that could take place for handicapped and nonhandicapped alike. 35

\section{Puppetry and the Mentally}

Handicapped

Puppetry is also proving to be an invaluable aid in the education of the mentally handicapped. Linda Anderson, in an article entitled "A Travelling Handicapped Troupe," 
tells about five mentally handicapped students who travel and bring their creative talents to hundreds of school children in New York. The troupe has been recognized, by the National Committee of "Arts for the Handicapped," as one of the thirteen Model Site Programs in the country. To quote Matthew O'Connel, Director of the Westchester County Office of the Handicapped:

These presentations serve two very important functions. First, they state the theme of handicapped people overcoming powerful stereotypes and insurmountable obstacles, and then they illustrate that theme through the performance of puppeteers who are themselves handicapped. Additionally, the shows succeed as pure entertainment, and this is an important consideration when you are trying to bring people around to a new point of view. 36

Anderson continues: "The cheers and applause given mentally handicapped students by 'normal children' gives them a sense of worth. . . The performance fosters a feeling of pride in these students, because they are able to bring joy to others, proving the point that disabled people are ABLE people." 37

Puppets and Language Teaching Whether disabled or able, research indicates that puppetry can and is being used to teach a wide range of subjects. Foreign langugges, one's ow janguges poetry, history, or lessons about a current problemand taught by way of puppets to children and adults everywhere.

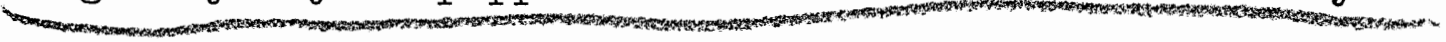


In a report from the Neufield Foreign Ianguage Teaching Materials' Project, David S. Rowland states: "The attraction of puppets can be most successfully explored in language teaching, both in providing a lively stimulus and as a means of building up the confidence of children in their ability to use the language. "38

Jacques C. Chicoineau calls puppetry a magnificent tool for teachers, especially teachers of foreign language. "It is 'par excellence' as an audio visual device, the most versatile, the most flexible, and the most portable, as it can be reduced to one or two puppets in the hands of the instructor." 39

Joseph S. Rubin, a technical specialist for the Multicultural Reading and Language Development Program at the Northwest Regional Laboratory in Portland, Oregon, developed what he calls "Benjamin Beaver's Box." According to Rubin, it has been successfully used in more than 185 rural Alaskan villages to help native Alaskan children learn to speak, read, and write English. Reports indicate that before the use of this tool, teachers were faced with a formidable problem. Rubin states:

The children were psychologically reluctant to speak English or even their native tongue because of the cultural "be seen and not heard" philosophy. With the introduction of the puppet, Benjamin Beaver, inhibitions are falling and English language development has been facilitated. 40 
Rob Gardner, commissioned by the Pennsylvania State Education Department to provide entertainment for the Vietnamese and Cambodian refugees in Pennsylvania, decided to present five puppet shows a day for the adult English classes. The shows served as a review of three months' work in the basic communication skills which were necessary for adaptation to American living. Nineteen shows, over a four-day period, were presented to 1500 people. They were well received by students and teachers and Gardner realized that "Puppets truly speak a universal language."4l

\section{Puppets and Language Arts}

In New York City, an experiment was carried out by the New York Board of Education to determine the effectiveness of using puppetry in the school language arts' program. Kindergarteners through eighth graders participated in the study. Shadow puppets, glove puppets, marionettes, and masks were utilized. It was found that through puppetry the children became aware of the importance of sequence, they enriched their vocabularies, they held discussions on plot, script, and production, and they gained a greater interest in classical music. They had to carry out research on topics which included geography, history, and current affairs. Marshall reports that they had an evident eagerness to improve their speech. Problem children, too, "finding that they were depended upon to do their share, 
did a good job. This experiment showed that if used in the right way, puppetry can become a dynamic medium in the field of education." 42

In another article entitled, "Bringing Books Alive Through Puppets," 43 Johnson encourages the use of puppetry in the teaching of children's literature. She writes:

Not only do children learn about the characters which the puppets represent, but they also enjoy emotional release when using them. Puppeteering has often proved to be the first step for the inarticulate child toward development of oral

Charlotte Kohrs, a speech and reading specialist, has found puppets invaluable in teaching phonics in reading. As a result of her experimentation, she has written a book entitled Puppets in Phonics and Reading. 45

Michael R. Malkin of the Speech Communications Department at California Polytechnic State University, who is also an actor and director of the Malkin Puppet Players, states:

Puppets and poetry are an irresistible combination for inspiring a number of Language Arts activities. When children converse through puppet characters, they easily lose their inhibitions and get involved in oral reading and interpretation of
poetry. 46

He also found that the more professional looking the puppets were the more children wanted to use them, and that it was better to provide the puppets himself for that kept the focus on the purpose of the lesson, the interpretation and presentation of the poem. 
In citing the benefits of puppetry, Malkin cites motivation, help for shy or embarrassed readers, background for future units on theater, as wel1 as what he considers the most important, fun while having a valuable learning experience. 47

Lois Koenig and Leila Weisholz have developed a special program for kindergarten children through grade seven entitled, A Pocket Full of Poems. Produced as an aid for developing Language Arts skills, Koenig contends that puppets add clarity and motion to difficult teaching problems. "Poetry, with its intense abstractions, vivid imagery and deep feeling, is represented in beauty and understanding through a puppet. The poem's meaning becomes clearer and student thought and discussion are initiated." 48

\section{Puppetry and Social Studies}

In the social science area, history and current events are effectively being presented via puppets. In the Mount Diablo Unified School District in California, one of the few districts that has a puppetry consultant on their staff, puppets perform as historical figures and children gain firsthand insight into the lives and actions of historical figures and events. 49

Puppets haze also been utilized in the field of crime and delinquenctuprevention. One such project is "The Learning Tree," a full-sized animated tree, which, operated 
from within, acts as narrator and puppet theater. It

presents the story of Dopey Dan and the Danger Man. Aimed

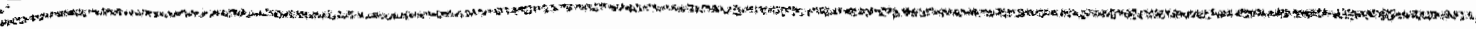

at lower elementary grades, the story presents the dangers of drugs, glue sniffing, smoking, careless use of matches, and stealing. The program, presented in Michigan under the auspices of the Macomb County Probation Department, reached nine thousand children its first year. A report from the performances indicates "Children listened and watched intently. They applauded when the villaj.n was alken to jail for all of his wrong doings. 150

In Pennsylvania a group of fourth and fifth graders learned about energy through a puppet project as an extravagant lady sang, "Gas, gas, give me gas." 51

Their teacher reported, "I feel that this two month unit on energy was an excellent example of education at its best. The students became acquainted with the academic and practical aspects of a very important subject which is touched on only lightly in most textbooks. "5?

Attempts are also being made to influence adults toward social change. In India, where overpopulation is a problem, puppetry is used as an instrument for teaching social change. Being an historical accepted medium in that country, various messages dealing with birth control have been presented, with interest being demonstrated by audiences. Literacy House in Iucknow, India has used puppetry in its literacy endeavors for years. In one Indian. 
village, 403 people lined up to vaccinated after they witnessed a puppet play about the dangers of smallpox. 53

\section{Puppetry and Mathematics}

Bruce Chesse, a California puppetry resource teacher, states: "Puppets are valuable aids in many fields of learning." In a special mathematics project, he had students first make puppets and then build a stage utilizing their knowledge of measurements. They were then required to devise a means to teach or illustrate some basic concept in new math. As a result of this project at the Larkey School, Mr. Chesse believes that puppetry can clarify a concept and that the student who can illustrate a concept retains it far longer. He also feels that puppets made by the students serve as reminders of what they did with them, therefore concepts are retained. He believes that the more fantastic the puppet, the greater the retention. 54

Like much of the art of puppetry, what has been done with puppets and mathematics has not been widely recorded. However, Patricia Hook reports that through the use of puppets, children who have met with frustration have learned that math can be "interesting and fun." 55 This is no surprise, for children are already learning that math can be fun on "Sesame Street" with Count von Count. Preschoolers are learning to count to 10 or 20 , and some are learning to understand that the number system extends beyond those 
which they have learned, and that larger numbers are used to count large numbers of objects.

\section{TELEVISION'S INFLUENCE ON PUPPETRY}

"Kukla, Fran and Ollie," "Sesame Street," and "The Muppets" are credited by most writers in the field of puppetry with having given impetus to the increase in use of puppetry in education. Teachers have observed that children who watched "Sesame Street," "The Muppet Show," or spot announcements and commercials which employed puppets have a store of knowledge that children previously did not have. Seeing the success that children's programming which involved puppets presenting educational concepts was having, teachers began borrowing and innovating.

Studies have been done by Ball and Bogatz on the effect of "Sesame Street" on children's learning. Findings based on an extensive amount of measurable data were: "The more viewing the child did, the more he tended to learn the projected concept; formal supervision of learners was not essential." 56

Chiconeau states: "Television producers are aware of the ability of children to learn from puppets, that is why they are so important in educational programing. "57 


\section{PUPPETRY AND POLITICS}

Long before the advent of television, the importance of puppetry was realized by Communist leaders in Eastern Europe. In Poland, Hungary, Czechoslovakia, and Russia there are over 200 government supported puppet companies, because the government recognizes the educational and attitude-forming power of the performing arts.

In these countries children and adults alike view puppet plays which present messages designed to indoctrinate. Building on the influential heritage of the medium, puppetry is used to spread governmental messages to the "unlettered masses." The spread of information is not only considered important, but is also considered educational, so theater including puppetry is considered a part of the educational system. Bil Baird tells us that puppet shows are often the children's first indoctrination. 58

\section{EMPIRICAL DATA VERSUS ANECDOTALISM}

Although empirical data has not been present in most of the foregoing literature, this researcher feels that the large number of anecdotal reports available in the field give much validity to the claim that puppetry is a valuable educative medium.

Herbert Simons in an article entitled, "In Praise of Muddleheaded Anecdotalism" states: 
The orthodox empiricist derives narrowly circumscribed research questions from a broader theory, and then brings homogeneous sets of data to bear upon each question. . . The anecdotalist derives general principles from his theory (rather than formally deduced hypotheses), and then brings heteregeneous examples to bear upon them. Internal validity is often in question, but one more frequently gets a sense of external validity. . . I would prefer at this point that we conceive of anecdotalism and orthodox empiricism as complementary approaches to both theory building and theory testing. 59

\section{EMPIRICAI STUDIES}

Puppetry researchers have been primarily anecdotalists, and the generalizations drawn from their anecdotes appear sound. However, a few empirical reports have surfaced recently. One is by Carolyn G. Maurer, entitled, "of puppets, feelings, and children" (as written). She reports on a specific study dealing with a group of 18 four-yearolds, from a rural area in North Central Florida, who were unable to verbalize their emotional experiences. As she stated, "They seemed unable to identify even the basic emotions of fear, anger, sadness, and happiness." A fourweek feelings unit was designed. It included the introduction of one feelings topic per week. Each lesson began with a puppet story presented by the counselor. After the presentation of the story, the counselor led a discussion of the focal feeling. The children were then encouraged to relate or role-play their experiences of that feeling. An overall evaluation of the unit by the counselor, the teacher, 
and the teacher-aide indicated the unit was effective. An informal assessment of the children's growth in feelings identification was made, utilizing an instrument developed by Maurer. The instrument consisted of smiling, sad, and neutral faces and was administered to the children. Quoting the author, "Although the results of these data were generally positive, the use of the instrument proved too difficult for many in the classroom, so specific data results were considered inconclusive, but inability to use the instrument should not be used to judge the value of puppetry." The author concludes that "Puppetry, as a means of facilitating the expression of feelings, taps the young child's world of fantasy and imagination and thereby allows learning to occur naturally and effectively."60

In 1974 Richard Warren Trullinger undertook to empirically assess the value of puppets as a teaching method for a specific language concept. Concepts above the grade level of the subjects were chosen as subject matter for the study. A pretest/posttest design was employed. The overall posttest results revealed that more than $90 \%$ of the subjects responded accurately to the test items for both of the concepts presented, thus indicating that puppets were an effective instructional medium. 61

In 1977 at Portland State University, Professor Robert Vogelsang, Professor Eduardo Saubidet, and Deborah Sullivan investigated the idea "that puppets are looked upon by most 
adults as a 'toy' or 'entertainment,' where in fact their use with children (adults) as a teaching, therapy, and communication medium are highly effective. This is true regardless of age, sex, and educational or cultural backgrounds." To prove their assumptions, an original puppet story was written entitled "Iisten to Floyd." One hundred forty children were used in their experimental group. They experienced the live puppet story. Eight trained interviewers questioned 59 of the children at the conclusion of the story. Six questions were used, the final one dealing with the theme of the story. Of the 59 children, $75 \%$ were able to identify with the theme of discrimination in the story, $75 \%$ identified the plot correctly, and $76 \%$ were correct in their character identification. The statistics enumerated, and others found by the researcher, empirically substantiated the researchers' assumptions. 62

\section{SUMIMARY}

Puppets are exciting, curious, Iifelike, and intriguing to people of all ages. This chapter has touched briefly on the origin of puppetry and includes just a few representative examples of its many uses. Little empirical data exists to prove the value of puppets in education, but a great deal of anecdotal information can be found. Books and periodicals abound with examples of how to make and use puppets. Their use on television has become common, and 
now even a new feature film, "The Muppet Movie" has been produced.

Research is constantly being carried out in the field of educational puppetry. The Puppeteers of America, through the Puppetry Journal, are endeavoring to increase and expand the educational uses of puppetry. The newly formed Puppetry in Education organization, publishing the Puppetry in Education News, is presently publicizing what is being done in the field. In England, the Educational Puppetry Association is constantly engaged in research in the field, and in Hungary a new research project on educational puppetry has just been initiated.

Puppetry in education has come of age. More empirical data will undoubtedly surface soon. 
Chapter 2--Notes

${ }^{I_{A}}$. R. Philpott, Dictionary of Puppetry (Boston: Plays Inc., 1969), p. 107 .

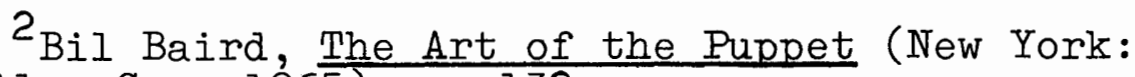
Macmillan Co., 1965), p. 132 .

${ }^{3}$ Sergei Obraztsov, The Chinese Puppet Theatre, cited by Bil Baird in The Art of the Puppet (New York: Macmillan Co., 1965).

$$
\begin{aligned}
& { }^{4} \text { Baird, p. } 46 . \\
& { }^{5} \text { Philpott, p. 233. } \quad 6 \text { Baird, p. 30-34. }
\end{aligned}
$$

7 Robert Bruce Inverarity, The Art of the Northwest Coast Indians, 2nd ed. (Berkeley, California: University of California Press, 1967).

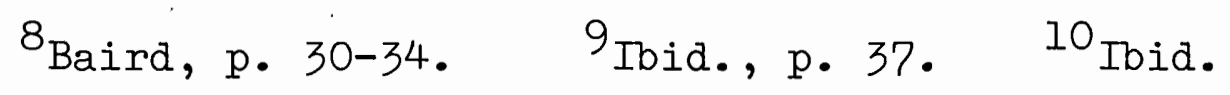

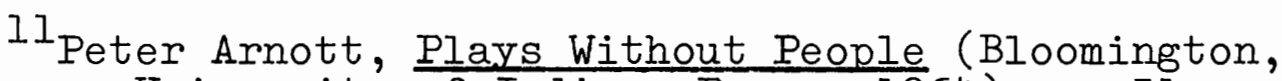
Indiana: University of Indiana Press, 1964), p. 31.

12 Baird, p. 65-68.

${ }^{13}$ Roland Sylwester, "The Puppet in the Church," Puppetry Journal (Jan.-Feb. 1972), p. 3-4.

14 Mary Ann Spencer Pulaski, Understanding Piaget

(New York: Harper Row, 1971), p. 96-117.

${ }^{15}$ David S. Rowland, "A Puppet Theatre for Language Teaching" (Leeds, England: Neufield Foundations, May 1965), p. 4 .

16 Nancy Quisenberry and Margo Willis, "Puppets as Learning Tools," Language Arts (Sept. 1975), p. 883.

17 Tbid., p. 883-885.

18 David Currell, Puppetry for School Children (Newton, Mass.: T. Branford Co., 1970), p. 7-8.

19Elizabeth Williams, "Helping Children Feel Like Someone Else and Talk Like Someone Else, "Elementary Fnglish (Jan. 1967), p. 57-58, 61 . 


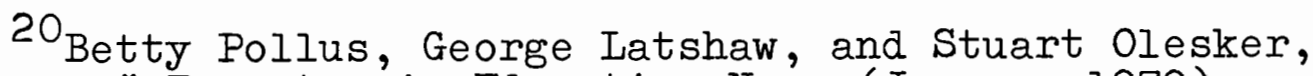
"Dialogue," Puppetry in Education News (January 1979), p. 9-10.

${ }^{21}$ A. R. Philpott, Puppets and Therapy (Boston: Plays Inc., 1977).

22 Simone Marcus, "Therapeutic Puppetry," Puppet Post (Summer 1948), cited in Puppets and Therapy, ed. A. R. Philpott (Boston: Plays Inc., 1972), p. 14 .

23 Toid.

24 Joanne Dunhill, "The Diagnostic Potential of Puppets," in Puppets in Therapy, ed. A. R. Philpott (Boston: Plays Inc., 1977), p. 149.

25 Tbid., p. 153.

26 Dorothy Delano, "Workshop: Defining Student Speech Problems," School Management (Feb. 1967), p. 11 .

27 Margaret S. Gordon, "Puppetry in Speech Clinics," Puppet Post (Spring 1953).

28 Ibid.

2.9 Jean Reges Burn, "Improving the Self Concept of the Exceptional Child," Puppetry. Journal (Sept.-Oct. 1978), p. 3-10.

30 Nancy Renfro, "An Enlightening Experience:

Learning from the Handicapped," Puppetry in Education News (Jan. 1979), p. 6 .

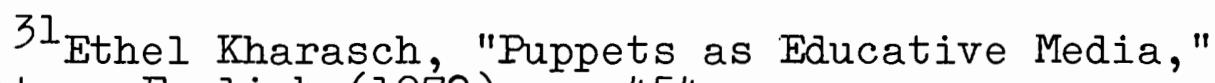
Elementary English (1972), p. 454 .

32 Violet Philpott, "Puppetry and Deaf Children," cited in Puppets and Therapy, ed. A. R. Philpott (Boston: Plays Inc., 1977), p. 67 .

${ }^{33}$ Ruthmarie Sheehan, "A New Vision Through Puppets," Puppetry in Education New' (November 1977), p. 5.

${ }^{34}$ R. Reich, "Puppetry--A Language Tool," Exceptional Child (April 1968), p. 621-623.

35 Betty Pollus, "Using 'Wheeler' to Mainstream," Puppetry in Education News (January 1979), p. 8-9. 
${ }^{36}$ Linda Anderson, "A Travelling Handicapped Troupe," Puppetry in Education News (May-June 1979), p. 8.

37 Ibid. $\quad 38_{\text {Rowland, }}$. 4.

39 Jacques C. Chicoineau, "The Use of Puppetry in the Teaching of Foreign Ianguage," in Current Approaches to the Teaching of Foreign Language, by Martin T. Barrett, Midwest Modern Ianguage Association (October 1972).

40 Joseph S. Rubin, "Benjamin Beaver's Box," Elementary English (1973), p. 619-623.

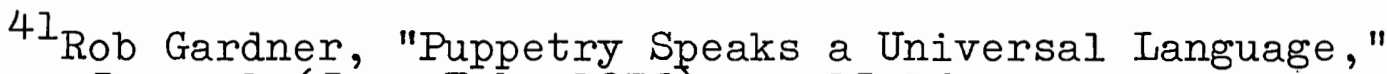
Puppetry Journal (Jan.-Feb. 1976), p. 15-16.

42 Currell, p. 8.

${ }^{43}$ Victoria. S. Johnson, "Bringing Books Alive Through Puppets," Elementary English (October 1966), p. 673.

44 Ibid., p. 674 .

${ }^{45}$ Charlotte Kohrs, Puppets in Phonics and Reading

(San Diego: Creative Children's Press, 1976).

46 Michael R. Malkin, "The Pleasures of Puppets and Poetry, " Teacher (October 1974). p: 66.

47 Ibid., p. 66-72.

${ }^{48}$ Lois Koenig and Leila Weisholz, "Puppets and Poetry," Puppetry in Education News (May 1978), p. 35.

${ }^{49}$ Bruce Chesse, "Puppetry in Education," Puppetry Journal (Nov.-Dec. 1975), p. 3-11.

50 Philpott, Puppets and Therapy, p. 100.

${ }^{51}$ Murray Engle, "Puppets Add Zest to Children's Study of Energy," Puppetry Journal (July-August 1974), p. 32-33.

52 Ibid., p. 33.

53 Bil Baird, Puppets and Population (New York: World Education Inc.), p. 11 .

${ }^{54}$ Chesse, p. 3-11. 
55 Patricia Hook, "Creative Math with Puppets," Puppetry Journal (Jan.-Feb. 1976), p. 7 .

${ }^{56} \mathrm{~S}$. Ball and G. Bogatz, "The First Year of Sesame Street; An Evaluation" (Princeton, New Jersey: Educational Testing Service, 1970).

57 Chiconeau, p. 1 .

58 Baird, Puppets and Population, p. 194-198.

59 W. Herbert Simons, "In Praise of Muddleheaded Anecdotalism," Western Journal of Speech Communication (Winter 1978), p. 27 .

${ }^{60}$ Carolyn G. Maurer, "of puppets, feelings, and children," Elementary School Guidance and Counseling (October 1977), p. 26, 31 .

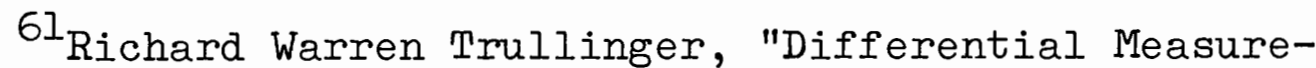
ment of a Language Concept Presented Via Videotape Playback to First Grade Students" (M.S. thesis, Portland State University, 1974).

${ }^{62}$ Robert Vogelsang, Eduardo Saubidet, and Deborah Sullivan, "The Development of Positive Attitudes and Social Values in Children Through Puppetry--or--Iisten to Floyd," Puppetry Journal, forthcoming. 


\section{CHAPTER III}

\section{METHODS AND PROCEDURES}

The present investigation was designed to assess the value of puppets as an instructional medium for teaching selected nutritional concepts to preschool, kindergarten, and first grade students.

\section{HYPOTHESES}

There were four hypotheses for this study. Null Hypothesis 1: There will be no significant difference in increase in knowledge of selected nutritional concepts for preschool, kindergarten, and first grade students when puppets are used as the instructional medium than when dramatic storytelling is used as the instructional medium.

Null Hypothesis 2: There will be no significant difference among the mean change scores of preschool, kindergarten, and first grade students in this study.

Null Hypothesis 3: There will be no significant difference in the mean change scores among preschool, kindergarten, and first grade 
students as a result of treatment (puppet storytelling or dramatic storytelling) in this study.

Null Hypothesis 4: There will be no significant difference in change scores between male and female subjects in this study.

\section{DEFINITIONS}

Selected nutritional concepts are defined in this study as (1) "Food gives you energy," (2) "you need energy to do active things," (3) "you are more likely to tire easily when you don't eat your meals," and (4) "you need to eat food from each of the four basic food groups each day." The basis for their selection will be explained in the section entitled "Pretest."

Preschoolers are defined as four- and five-year-old children who have not attended kindergarten.

Dramatic storytelling will be defined in the section entitled "Presentation of Dramatic Storytelling."

\section{DESIGN}

A pretest, posttest design was utilized for this study. In order to assess the value of the puppets themselves as the instructional medium, only one variable, the method of storytelling, was introduced. The experiment was designed to include a pretest, a puppet presentation of a 
story, and a posttest for the experimental group; the same pretest, a dramatic storytelling situation of the same story, and the same posttest for the control group. These were administered consecutively over a three-day period to each group. Classroom teachers participating in the study received instruction from the investigator not to discuss the concepts with the subjects until after posttesting was completed.

A variation in administration of the pretest and posttest was employed for the preschool children. This was necessary because of the age diversity of the subjects. Details of the variation will be subsequently explained.

For the experimental and the control group, the three components were administered over three consecutive days.

\section{SUBJECTS}

The subjects for this study consisted of 98 students enrolled in four first grade and two kindergarten classes at Lynch Plaza Elementary School; 29 students enrolled in one first grade and one kindergarten class at Lynch Park Elementary School; 14 children, aged four to five, at the Helen Gordon Child Development Center; and 13 students, aged four to five, enrolled at the Pixie Day Nursery. The only children from these groups who were not used for the study were four children who had been absent for one or more of the components of the study. They were allowed to participate, but their tests were disregarded. 
The Lynch Plaza students and the children from the Helen Gordon Child Development Center were used for the experimental group. The Iynch Park Students and the Pixie Day Nursery children were used for the control group.

The Lynch Plaza experimental group contained all of the morning kindergarten children and all of the first grade students, who were enrolled and present at Lynch Plaza Elementary School for all three components of the experiment: the pretest, the puppet story, and the posttest.

The Helen Gordon experimental group consisted of those students who attended a puppet presentation of the story on May 9, 1979 in the Portland State University Television Studio and who were in attendance at the Helen Gordon Center on the days of the pre- and posttests. Again, there was no selection process.

The Iynch Park control group consisted of all of the students enrolled and present in one first grade class and one kindergarten class at Lynch Park Elementary School who were present for all three components of the control situation: the pretest, the dramatic storytelling, and the posttest. These classes were selected at random.

The Pixie Day Nursery control group consisted of all of the preschool children who were in attendance at the nursery on the days when the three components were presented. 


\section{THE PRETEST}

\section{Pretest for Lynch Plaza and}

\section{Lrnch Park Elementary}

Schools

A paper and pencil pretest, based on the learning objectives, was constructed by the investigator in consultation with six primary teachers. Taking into account various modalities of learning--kinesthetic, auditory, and visual--a decision was made to use a combination of pictures, "yes/no" responses, and a few short answer items. Pictures were cut from a variety of sources and questions were con-. structed to fit the learning objectives.

The pretest was subjected to a pilot study with a second grade class at Rockwood Hartley Elementary School. The original draft of the pretest was administered. A very high success rate was attained by the students in the pilot study. Their scores ranged from $82 \%$ to $100 \%$ accuracy. An analysis of the results was conducted, and in consultation with three second grade teachers at Iynch Plaza Elementary School it was determined that second graders already had the knowledge which the puppet story was designed to teach. The original draft was then analyzed by kindergarten and first grade teachers and it was decided that it was too difficult for kindergarten and first grade students. A second test, based on the learning objectives (see Appendix A) and their suggestions of better spatial arrangement, 
larger print, marginal pictures, and fewer "yes/no" questions was then prepared.

Upon the advice of kindergarten teachers, food items were placed in the margin by each question as points of identification so that nonreaders would be more likely to respond to the correct set of pictures and answers.

This test was then administered to a kindergarten and a first grade class at Margaret Scott Elementary School. Scores ranged from 49\% to 91\%. No significant differences in the scores occurred in the kindergarten and first grade groups. The investigator and six of the teachers, who were to be involved in the experiment, then determined that the test would be an appropriate measuring device for the concepts to be presented. No specific reliability tests were conducted, because this researcher felt the teacher consultation involved in the preparation was adequate to make the test valid.

\section{Pretest for Helen Gordon Center}

\section{and Pixie Day Nursery}

In preparing the pretest to be used with preschoolers, the administrator of the Helen Gordon Center was consulted. At her suggestion, the paper-pencil test constructed for use in the Iynch Schools was converted to an interview format. She felt the kinesthetic and oral method would provide a more reliable measure of the preschoolers' knowledge. 
The investigator concurred with this idea, because research indicates preschoolers are more able to respond in those modalities. Children at the age of four and five are able to learn many of the same concepts as kindergarten and first grade children, but they are unable to respond in the same modality. That is, paper-pencil tests do not provide a reliable measure of their knowledge.

Using this logic, the same pictures which were used in the paper-pencil test were mounted on $5 \times 7$ inch cards and $8 \times 11$ inch sheets, so that they could be shown to the children in a one-to-one situation in a nonconfusing manner.

For the "yes/no" questions, the test was designed so that each child was asked the question orally and his or her response was recorded as correct or incorrect on a prepared chart indicating the number of the question. Total scores per child were obtained by adding the number of correct responses and converting the number of correct responses to a percentage figure.

The paper-pencil pretest was given by the investigator on Monday, May 21, 1979 in four first grade classrooms and two kindergarten classrooms at Lynch Plaza Elementary School. It was also given to a first grade class and a kindergarten class at Lynch Park Elementary School on Monday, June 11, 1979. Time required for the test was approximately 20 minutes. Children were seated at their desks in their own classrooms for the pretest. Where 
necessary, cardboard dividers were used to prevent children from seeing each others' papers. All children present in each of the classrooms were tested, with the classroom teacher observing the procedure.

The investigator entered each classroom at a preplanned time and was introduced, by name only to the children. To the Iynch Plaza experimental group the investigator explained her presence as follows:

Hello boys and girls. I would like to invite all of you to come to the library tomorrow morning at 9:00 o'clock. Some puppets will be visiting and will tell you a story about good foods. But, before you see the puppets and hear the story, I would like to find out what you already know about good foods, so I have prepared this little booklet (pretest) and I would like to go through it with you.

Would you please look at it now. Put your name on the top line. Now, on the line right under your name, would you put a K (or a $l$ if a first grader).

As we go through the booklet, I will read the question, and you will circle the picture or the answer that you think is correct.

You probably won't know the answers to all of the questions today. Don't guess! Tomorrow, when you see and hear the puppet story, you'll learn the answers to the questions, which you can't answer today. When I return on Wednesday, we'll do this again, and then you'll know all of the answers.

Are you ready? Put your finger on the apple. Look at the two faces in that row, circle the face that shows how you feel when you eat your breakfast. Ready? Now put your finger on the . . .

Students proceeded through the test in this fashion, item by item, with the investigator reading all of the instructions and waiting for the students to mark their papers. This was to make certain that nonreaders were able to respond on the basis of their knowledge, not their reading ability. 
For the control groups at Lynch Park Elementary School, the investigator was again introduced, by name only, to the children. There she explained her presence as follows:

Hello boys and girls. Did you have a good time at the zoo Friday? Good! Today I have something else a little special for you, too. I have a booklet (pretest) here that has some questions and pictures in it. I would like you to go through it with me, and mark the pictures and the questions that you can. Then, tomorrow, I will come back and tell you a special story called Granny Goody's Magic Food Pot.

But, before you hear the story, I would like to see what you already know about good foods.

Would you please look at it now. Put your name on the top line. Now on the line right under your name, would you put a $\mathrm{K}$ (or a $l$ if a first grader).

As we go through the booklet, I will read the question and you will circle the picture or the answer that you think is correct.

You probably won't know the answers to all of the questions today. Don't guess. Tomorrow when you hear the story, you'll learn the answers to the questions which you can't answer today. When I return on Wednesday, we'll do this again, and then you'll know all of the answers.

Are you ready? Put your finger on the apple. Look at the two faces in that row, circle the face that shows how you feel when you eat your breakfast. Ready? Now put your finger on the ... .

Students proceeded through the test in this fashion, item by item, with the investigator reading all of the instructions and waiting for the students to mark their papers.

For the administration of the pretest to the experimental group at the Helen Gordon Child Development Center, the investigator arrived at the Center on Monday morning and became acquainted with the children. When the children 
were at ease with the investigator, they went with the investigator, one at a time, to their lunchroom.

Seated next to the investigator, each child was shown a series of cards containing pictures and was asked to respond by pointing to the picture of their choice in response to the question. The investigator said:

Look at these two faces. Show me which one you'd feel like, if you ate your breakfast. Which of these boys do you think ate his breakfast? . . etc.

For the "yes/no" questions on the test, each child was asked the question orally and his, or her, response was recorded on a prepared chart indicating the number of the question. The same procedure was used on a subsequent Monday for the control group at the Pixie Day Nursery.

\section{PREPARATION OF STORY SCRIPT}

The purpose of this study was to assess the value of puppets as an instructional medium for teaching selected nutritional concepts to preschool, kindergarten, and first grade students. Basic state-adopted primary textbooks, ${ }^{2}$ as well as the National Dairy Council's Food: Your Choice, Leve $11^{3}$ were consulted. From these sources, learning objectives appropriate to preschool, kindergarten, and first grade were determined. They were: "Food gives you energy; you need energy to do active things such as run and play; you are more Iikely to be tired when you don't eat your breakfast; you need food from each of the four basic groups each day." 
Once the objectives had been determined, the investigator, in cooperation with Professor Robert Vogelsang, Teresa Breidenbach, and Candy Copley, wrote a puppet play entitled "Granny Goody's Magic Food Pot."

Through experimentation and rehearsal, the script was revised several times by the investigator until the final dialogue was developed. The most important final addition was the addition of planned questions to encourage student involvement throughout the play. This form of the story was used for the experimental group. For the control group, the puppet dialogue was converted by the investigator into a dramatic story (see Appendix B).

\section{THE PUPPETS}

Two puppets were constructed. Granny Goody, constructed by the investigator, was a large, life-size, felt hand puppet. For her construction, a basic muppet pattern was enlarged. The head and hands were made from fleshcolored felt reinforced with easy shape interfacing. The head was given form by inserting molded foam. Foam rubber was also used to form the torso and cotton batting was utilized to complete all shaping. Granny's hair was white polyester yarn. It was stitched into the top seam on the puppet's head. The eyes were cut from black and white felt and the cheeks were make of pink felt, as was the mouth. All were attached with craft glue. The nose and ears were 
of molded, stuffed flesh-colored felt. Glasses were purchased at the Good Will and stitched to the puppet at the ears. Granny's dress was a cotton print and her apron was made of blue denim. A rod was attached to the puppet's left arm for manipulation purposes. (See Appendix C.) Jody, constructed by Professor Robert Vogelsang, was also a hand puppet. His head was sculpted from a styrofoam block and covered with flesh-colored felt. The mouth was hinged for manipulability and the features were highlighted with a combination of paint and felt. Jody's body and limbs were constructed of rolled paper. His hands and feet were felt. Jody's trousers were blue denim, his shirt was a plaid cotton, and his hat a navy blue. Cub Scout hat. Rods were attached to both wrists for manipulative purposes. (See Appendix C.)

\section{PROPERTIES AND THEATER}

A backdrop for the puppet play was constructed by the investigator. Paper food models from a kit entitled Food: Your Choice, Ievel 1, ${ }^{4}$ were attached by way of double-stick tape to a blue cotton backdrop. Green contact vinyl strips, one inch by six feet, were cut and attached to the blue backdrop to simulate shelves. The entire background was then covered with clear contact vinyl to assure stability.

Puppet properties were also constructed by the investigator. One side of a paper bag was dry mounted on a tag 
board and then attached to a metal rod, so that it could be attached to the stage at the appropriate time. This was Jody's lunch sack. Breakfast was constructed by attaching two models of a bowl of cereal, two models of bowls of strawberries, and two models of glasses of milk to each other back to back. A metal rod was inserted between the back sides of each and the assembled prop was covered with contact vinyl, so as to hold the breakfast, as constructed, intact. Other props constructed similarly were cheese, peanuts, and apple, a banana, and a roast beef sandwich. Food models from the Food: Your Choice ${ }^{5}$ kit put out by the National Dairy Council were the starting items for each prop. (See Appendix C.)

A portable puppet theater approximately 6 feet $\mathrm{x}$ 8 feet $x 3$ feet, belonging to Professor Robert Vogelsang, was utilized for the presentation of the puppet show.

\section{PRESENTATION OF PUPPET STORYTELLING}

The investigator and Lacey Vogel, an elementary education major, rehearsed the puppet story for approximately 30 hours. The puppet story was presented live, with the investigator and one other individual, Lacey Vogel, as puppeteer/actors. The first presentation for the experimental group from the Helen Gordon Center was on May 9, 1979 in the Portland State University television studio. This location was chosen because of the desire to videotape 
the story for future use. (Color videotape is available in the Portland State University Television Studio archives.)

The children entered the television studio and were seated on chairs. Dr. Robert Vogelsang greeted the children and introduced the puppet story. The live presentation then took place. At the conclusion of the puppet story, the investigator and Lacey Vogel mingled with the children and invited them to manipulate the puppets.

The presentation for the second experimental group was in the Iynch Plaza Elementary School library on May 22, 1979. The subjects from the six classes, comprising this experimental group, entered the library and were seated on the floor. The investigator greeted the children and introduced the puppet story. Lacey Vogel, as Jody, and the investigator, as Granny, then presented the puppet story, "Granny Goody's Magic Food Pot." At the conclusion of the story, the puppeteer/actors were introduced to the children and the children were invited to ask questions.

\section{PRESENTATION OF DRAMATIC STORYTELLING}

The investigator rehearsed the story for approximately four hours so that she would be able to present the same story without the assistance of another individual and without the assistance of properties or puppets. The dramatic story presentation for the control group took place on June 12, 1979 at Lynch Park Elementary School. The 
investigator entered each individual classroom at the prearranged time and was introduced by name only to the children. In each situation the children were seated on the story rug in their individual classrooms. The investigator began:

It is nice to see you again, boys and girls. Today I am going to tell you a story about a boy named Jody and his grandmother, Granny Goody. The name of the story is Granny Goody's Magic Food Pot.

The story was presented in the fashion of dual dram-atic acting with sound effects, storyteller moving about, and assuming postures and voices for the two characters. (The script, as used, is included in Appendix B.) At the conclusion of the story the investigator thanked the children and told them that she would be back to see them again the next day. The story presentation for Pixie Day Nursery also took place on June 12, 1979 in the preschool classroom. The same procedures used at Lynch Park Elementary School were used at the Pixie Day Nursery.

\section{THE POSTTEST}

Using a random numbers table, ${ }^{6}$ all items and questions on the pretest were rearranged for the posttest. The randomized paper-pencil posttest (see Appendix A) was administered to the six experimental groups in their individual classrooms at Lynch Plaza Elementary School on May 23, 1979, and to the two control groups at Lynch Park Elementary 
on June 13, 1979. The same procedures used in the pretest were used in the posttest. The randomized interview posttest was administered to the experimental group at the Helen Gordon Child Development Center on May 10, 1979, and to the control group at the Pixie Day Nursery on June 13, 1979. Again, the same procedures utilized in the pretest were employed in the posttest.

\section{DATA ANALYSIS}

Tests were scored by the examiner. A correct answer on each item was given a value of $I$ on pre- and posttests. This made a total of 32 points for each test. Results were converted to percentages for the pretest and the posttest. The change scores were found by subtracting the pretest score from the posttest score. The purpose was to see if the change scores would differ between experimental and control groups; among preschool, kindergarten, and first graders in the total study; and among presechoolers, kindergarten children, and first graders as a result of the treatment. Male and female change scores were also compared.

A Pearson product moment correlation was computed to determine how low pretest scores were associated with high change scores. The percentage of pretest scores which fell below the mean in the experimental and control groups was also calculated to make certain that there was no significant 
difference between the two groups. The standard deviation from mean change scores was also determined for control versus experimental in the overall study and within each grade level.

To further test the hypotheses, a t-test of independent means was computed with $\mathrm{x}$ being the change score of all experimental subjects and $y$ being the change score of all control subject. 
Chapter 3--Notes

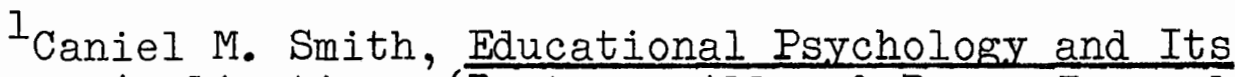
Classroom Applications (Boston: Allyn \& Bacon Inc., 1978), p. 75-78.

${ }^{2}$ Eldonna Evertts, Iyman C. Hunt, and Bernard J. Weiss, About Me (New York: Holt, Rinehart and Winston Inc., 1973); Julius B. Richmond, Elenore T. Pounds, and Irma B. Frickes, Health and Growth I (Illinois: Scott Foresman Co., 1971), p. 42-60; Idem, Health and Growth 2, p. 97-112; Julius B. Richmond and Elenore T. Pounds, You and Your Health; School, Home and Community (Illinois: Scott Foresman Co., 1977), Level 1, p. 90-101; Level 2, p. 70-87.

3Fod: Your Choice, Level 1 (Illinois: National Dairy Council, 1977): (Kit.)

${ }^{4}$ Ibid. 5 Ibid.

${ }^{6}$ Sarah M. Dinham, Exploring Statistics: An Introduction for Psychology and Education (California: Brooks Cole Publishing Co., 1976), p. 255-256. 


\section{CHAPTER IV}

\section{RESULTS AND DISCUSSION}

The purpose of this investigation was to assess the value of puppets as an instructional medium for teaching selected nutritional concepts to preschool, kindergarten, and first grade students. The essential question was: Will preschool, kindergarten, and first grade students have a greater increase in knowledge of selected nutritional concepts as a result of viewing a puppet story than a similar composite of students will have when the same material is presented via dramatic storytelling? Secondary questions were:

1. Will change scores be significantly different among the preschool, the kindergarten, and the first grade levels?

2. Will treatment (puppet or dramatic storytelling) cause change scores to be significantly different among preschool, kindergarten, and first grade students?

3. Will there be any difference between change scores of male and female subjects in this study? 


\section{RESULTS}

The results of the investigation will be presented in the order of the four hypotheses.

Null Hypothesis 1: There will be no significant difference in increase in knowledge of selected nutritional concepts for preschool, kindergarten, and first grade students when puppets are used as the instructional medium than when dramatic storytelling is used as the instructional medium.

Based on the mean of the pretest, which was $71.06 \%$, and the mean of the posttest, which was $89.59 \%$, the mean change score for the subjects of the experimental group who received instruction via puppets was $18.53 \%$.

Based on the mean of the pretest, which was $64.36 \%$, and the mean of the posttest which was $72.31 \%$, the mean change score for students in the control group who received instruction via dramatic storytelling was $7.95 \%$.

These statistics indicate that the mean change score when puppets were utilized as the educative medium was $11.58 \%$ greater than when dramatic storytelling was employed as the educative medium. (See Table I.) 
TABLE I

COMPARISON OF EXPERIMENTAL AND

CONTROL GROUPS' MEAN SCORES

\begin{tabular}{l|cc}
\hline & Experimental & Control \\
\cline { 2 - 3 } & $\%$ & $\%$ \\
\hline Mean pretest score & 71.06 & 64.36 \\
Mean posttest score & 89.59 & 72.31 \\
Mean change score & 18.53 & 7.95 \\
\hline
\end{tabular}

Because random assignment of student groups to treatments was restricted to a very limited number of total units, some preliminary tests on preexperimental equivalence were made. To determine what effect low pretest scores had on change scores, a Pearson product moment correlation coefficient was computed. There was an inverse relationship of -.41 between the pretest and the change scores which means the lower the pretest scores, the higher the change score. This was significant at the $\mathrm{p}<.001$ level. Because of the inverse relationship, it was important to ascertain the percentage of pretest scores which fell below the mean in experimental versus control groups. Forty-eight percent of the pretest scores of the control group fell below the mean as compared to $43 \%$ of the experimental pretest scores.

The investigator assumes from the data that the resulting statistics indicate that there was not a 
significantly greater proportion below the mean in one group or the other, but if it were significant, the benefit would be in the direction of the control group.

The standard deviation from the mean change score was $12.48 \%$ in the experimental group and $13.64 \%$ in the control group. The range of the mean change scores was $3 \%$ to $70 \%$ for the experimental group, and $-16 \%$ to $40 \%$ for the control group. (See Table II and Appendix D.)

\section{TABLE II}

COMPARISONS OF EXPERIMENTAL AND CONTROL GROUPS

\begin{tabular}{l|cc}
\hline & Experimental & Control \\
\cline { 2 - 3 } & $\%$ & $\%$ \\
\hline Mean pretest scores & 71.06 & 64.36 \\
$\begin{array}{l}\text { Pretest scores below } \\
\text { pretest mean }\end{array}$ & 43 & 48 \\
Mean change scores & 18.53 & 7.95 \\
Standard Deviation of & & 13.64 \\
Change scores & 12.48 & -16 to 40 \\
\hline
\end{tabular}

To test null hypothesis 1, a t-test of independent means was computed with $\mathrm{x}$ being the change score of all experimental subjects and $y$ being the change score of all control subjects. The t-test score for the comparison of the experimental and control group change score mean was 5.01 which was significant at the $\mathrm{p}<.001$ level, thus 
indicating that the resultant data was highly significant, thus rejecting the null hypothesis: there will be no significant difference in increase in knowledge of selected nutritional concepts for preschool, kindergarten, and first grade students when puppets are used as the instructional medium than when dramatic storytelling is used as the instructional medium.

Null Hypothesis 2: There will be no significant difference among the mean change scores of preschool, kindergarten, and first grade students in this study.

Based on the means of the pre- and posttests and the mean change scores of the three groups, the following data were discovered. Preschoolers had a mean change score of 27.89\%, kindergarten children had a mean change score of $16.23 \%$, and first graders had a mean change score of $11.35 \%$. (See Table III.) These overall statistics would seem to indicate that there was a significant difference among change scores of preschool children, kindergarten children, and first graders, and that the greatest gain was achieved by the preschoolers, the second greatest by the kindergarten children, and the least amount by the first graders. These statistics would seemingly reject null hypothesis 2, that there will be no significant difference among the change scores of preschool, kindergarten, and first grade students in this study. 
TABLE III

COMPARISON OF MEAN PRETEST, POSTTEST,

AND CHANGE SCORES BY GRADE LEVEL

\begin{tabular}{llcl}
\hline & Preschool & $\begin{array}{c}\text { Kinder- } \\
\text { garten }\end{array}$ & $\begin{array}{c}\text { First } \\
\text { Grade }\end{array}$ \\
\hline Total Study & $\mathrm{N}=27$ & $\mathrm{~N}=45$ & $\mathrm{~N}=82$ \\
Pretest & 52.81 & 63.73 & 78.83 \\
Posttest & 80.70 & 79.96 & 90.18 \\
Change score & 27.89 & 16.23 & 11.35 \\
\hline Experimental Group & $\mathrm{N}=14$ & $\mathrm{~N}=32$ & $\mathrm{~N}=66$ \\
Pretest & 51.79 & 68.59 & 77.80 \\
Posttest & 91.29 & 87.91 & 91.58 \\
Change score & 39.5 & 19.32 & 13.78 \\
Standard & & & 7.58 \\
deviation & 16.74 & 9.72 & $\mathrm{~N}=16$ \\
\hline Control Group & $\mathrm{N}=13$ & $\mathrm{~N}=13$ & 83.06 \\
Pretest & 53.92 & 51.76 & 84.43 \\
Posttest & 69.31 & 60.38 & 1.37 \\
Change score & 15.39 & 8.62 & 7.62 \\
Standard & 12.67 & 15.25 & \\
deviation & & & \\
\hline
\end{tabular}

Null Hypothesis 3: There will be no significant difference in the mean change scores among preschool, kindergarten, and first grade students as a result of treatment (puppet storytelling or dramatic storytelling) in this study.

Based on the mean of the pre- and posttests and the mean change scores of preschoolers, kindergarteners, and 
first graders the following data were discovered. In the experimental group, preschoolers had a mean change score of $39.5 \%$, kindergarteners had a mean change score of $19.32 \%$, and first graders had a mean change score of $13.78 \%$. In the control group, preschoolers had a mean change score of $15.39 \%$, kindergarteners had a mean change score of $8.62 \%$, and first graders had a mean change score of only $1.37 \%$ (see Table III).

The standard deviation from the mean change score was also computed for preschool, kindergarten, and first grade students in both the experimental and the control group (see Table III).

To test null hypothesis 3, separate t-tests of the independent means for each grade level were computed with $\mathrm{x}$ being the change score of the experimental subjects in each test and $\mathrm{y}$ being the control subjects in each test. The resulting data are found in Table IV.

TABLE IV

t-TEST COMPARISONS OF EXPERIMEINTAI AND CONTROL GROUPS' CHANGE SCORES

\begin{tabular}{lcc}
\hline \multicolumn{1}{c}{ Group } & t-test Scores & Significance \\
\hline Preschool & 3.96 & $\mathrm{p}<.001$ \\
Kindergarten & 2.81 & $\mathrm{p}<.01$ \\
First Grade & 7.16 & $\mathrm{p}<.001$ \\
\hline
\end{tabular}


Null Hypothesis 4: There will be no significant difference in change scores between male and female subjects in this study.

Based on the means of the pre- and posttests and the mean change scores, the mean change score for all male subjects in this study was 16.68, and the mean change score for all female subjects was 14.55. This indicates a greater gain of only $2.13 \%$ for male subjects over female subjects. Details of these statistics as well as the differences between male and female subjects in the control and experimental groups are enumerated in Table $V$.

\section{TABLE V}

COMPARISON OF MEAN PRETEST, POSTTEST, AND CHANGE SCORES BY SEX

\begin{tabular}{llll}
\hline & Pretest & Posttest & Change Scores \\
\hline Total Study & & & \\
Male $\mathrm{N}=82$ & 67.5 & 84.15 & 16.65 \\
Female $\mathrm{N}=72$ & 72.54 & 87.10 & 14.56 \\
\hline Experimental & & & \\
Male & 69.16 & 89.31 & 20.15 \\
Female & 75.22 & 91.90 & 16.68 \\
\hline Control & & & 6.52 \\
Male & 62.67 & 69.19 & 9.38 \\
Female & 66.05 & 75.43 & \\
\hline
\end{tabular}


These statistics indicate that overall, the male subjects had a greater gain of $2.13 \%$. They also had a greater gain of $3.46 \%$ when puppets were used as the instructional medium. The females had a greater gain of $2.86 \%$ when dramatic storytelling was the medium. This researcher did not feel that there was any cause to pursue further analysis of the statistics, since the differences were so slight and would appear to agree with the acceptance of the null hypothesis 4, that there will be no significant difference in the change scores of male and female subjects in this study.

\section{DISCUSSION}

The data resulting from this study, comparing puppet storytelling and dramatic storytelling are quantifiable and in some instances significant. The overall posttest scores of the experimental group revealed that a mean score of 89.59\% was attained when puppets were used as the instructional medium to teach selected nutritional concepts to preschoolers, kindergarteners, and first graders. Since the mean pretest score for this group was $71.06 \%$, the data reveal that in one 14-minute puppet presentation, the experimental subjects had a mean change score of $18.59 \%$ in their knowledge of the selected nutritional concepts. In contrast, the control group's mean pretest score was $64.36 \%$ and their posttest score was $72.31 \%$, which was a 
mean change score of $7.95 \%$. This was after being presented the selected nutritional concepts by way of dramatic storytelling. From these statistics it is apparent that the puppet storytelling method produced a significantly higher mean change score, $11.58 \%$, than did the dramatic storytelling method, thus rejecting null hypothesis 1 , that there will be no significant difference in increase in knowledge of selected nutritional concepts for preschool, kindergarten, and first grade students when puppets are used as the instructional medium than when dramatic storytelling is used as the instructional medium.

Of interest to this researcher was the fact that more of the experimental subjects attained higher change scores than did the control subjects. When puppet storytelling was used as the instructional medium, $74 \%$ of the subjects had change scores of the percent or higher. In contrast, only $28.5 \%$ attained change scores of $10 \%$ or higher when dramatic storytelling was the educative medium. The highest change score for control subjects was $40 \%$. This was achieved by one student. In contrast, a student in the experimental group had a change score of $70 \%$.

Also of interest in this study were the zero scores and negative scores which occurred in the dramatic storytelling group. One third of the subjects in the control group had no gain, or had a negative change score. Of that one third, 19\% of the control subjects had lower 
posttest scores that pretest scores. This zero or negative growth phenomena did not occur when puppets were utilized as the instructional medium.

The purpose of this study was to assess the value of puppets as an instructional medium for teaching selected nutritional concepts to preschool, kindergarten, and first grade students. To attain this goal, as few variables as possible were introduced. Two schools in the same school district were used for the kindergarten and first grade control and experimental groups. According to the principals, the student body composition was comparable at the two schools. Both schools were in an average middle-class suburban neighborhood within a two-mile radius of each other. The children in the preschool experimental group attended a child care center on the West side of Portland and the children in the control group attended a child care center on the East side of Portland, but the mix of parental background seemed comparable to this investigator. This was deduced from the conversations with the administrators of each of the centers.

To determine what factors caused the higher change scores when puppet storytelling was used, an analysis was made of the presentations. In the puppet story presentation and the dramatic storytelling presentation, the vocal expression and the mood were the same. However, in the dramatic storytelling, the children were aware that it was 
one person who was changing her voice to accomplish the characterizations. For visual focus, the experimental group had two colorful puppets, a stage, and props on which to focus. In contrast, for visual focus the control group had one actor, moving about, posturing, and gesturing. Since the words of the story were almost identical and the audio presentation was at least equally expressive, this investigator believes that the most important factor in the greater gain for the experimental group would have to have been the puppets themselves.

The next question that needed an answer then was what makes puppets a more effective teaching medium? In researching the literature several factors came to this investigator's attention. The first was that children identify with puppets, ${ }^{1}$ so if the puppet learns, the child who identifies with him learns. If this is true, since Jody, the puppet, learned that he must eat his meals, the children who identified with him also learned that concept.

The concept presented most strongly in the story was that children tire more easily and have no energy when they don't eat their breakfast. The children who saw the puppet story saw the puppet tired, they saw him when he said, "I've got energy!" When the children. who saw the puppet story were posttested, $100 \%$ of the subjects responded correctly to the questions dealing with this main concept. In contrast, the control subjects, who had no puppet with 
which to identify, but heard the same words and saw the storyteller act tired, did not respond to the main concept with any greater accuracy than any other idea presented in the story. In fact, nearly all of the preschoolers in the control group missed the point that food gives you energy. So, identification with the puppet seems to be an important factor as to why puppets are an effective medium and why the change scores were higher for the experimental group.

Another factor, which the researcher believes made the puppet method more effective, is that puppets are animated and visual, but so was the storyteller for the control group. What made the difference? Children from infancy are exposed and attuned to visuals. On the average, children view upwards of 30 hours of television each week. 2 They are used to color and action. Because of this conditioning, children's attention wavers when there is not enough variation in visual format. This researcher noticed the children's attention wavering during the dramatic storytelling. To compensate and regain their attention, she moved about more, and exaggerated her acting more. Being behind the stage during the puppet story, this investigator does not know whether attention wavered during the puppet presentation.

In reviewing the iiterature, puppets were called "par excellence" as audio visual aids and it was suggèsted 
that an important aspect of their appeal was their ability to attract and hold attention. Wavering attention in the control group was apparent in this study. For these reasons, this researcher believes it was the puppets themselves that facilitated learning.

There are, however, two other factors which might have had some effect on the outcome of the investigation. One is that both experimental groups viewed the puppet story in a special place. The preschoolers viewed it in the Portland State University Television Studio. This could have had a positive or negative effect. As they were in a special place, they might have been more attentive. On the other hand, since there was a large television camera in the middle of the room, a boom microphone, and bright lights, the children could have been distracted by the atmosphere. The children's posttest scores, however, would not lead this researcher to believe that they were distracted.

The kindergarten and first grade children in the experimental group saw the puppet story in the library. It was a treat and could have provided a plus factor for attentiveness. The large group situation, however, could also have acted as a negative factor.

All three control groups heard the story in their own rooms. They sat on their story rugs. The children were used to this situation and were comfortable. The only change for them was that a guest was telling the story, 
rather than their teacher, and the guest was acting out the story. This was not a method of storytelling that their teachers had used in any of the classrooms. This was ascertained by asking each of the teachers if they had ever used that particular method of storytelling. There was, therefore, an element of newness and change for the control group as well as for the experimental group, but possibly it was not as great for the control group.

The other factor which the experimenter noted was the teacher's attitude toward the experimental situation. The teachers were very happy to have a puppet story. The ones who were exposed to the dramatic storytelling expressed aloud the preference for the puppet show. This makes one wonder what the children's attitude was, and what effect their attitude had on their learning.

But whatever the reasons, the data as reported in the. results of this study, seemingly reject the null hypothesis that there will be no significant difference in increase in knowledge of selected nutritional concepts when puppets are used as the instructional medium for preschool, kindergarten, and first grade students than when dramatic storytelling is used as the instructional medium.

This researcher hypothesized that there would be no significant difference in the change scores registered between male and female subjects in this study. There was no attempt to equalize the number of boys and girls in each 
group since entire classes within each school comprised the composites for the groups. By chance there were 82 boys in the study and 72 girls. There were 51 girls and 61 boys in the experimental group and 21 boys and 21 girls in the control group. There was only a very slightly higher mean change score; 2.13\%, for the male subjects in this study. This greater gain was noted in the experimental group where the male mean change score was $3.46 \%$ higher than the female change score. In contrast, the female mean change score was slightly higher, $2.86 \%$, in the control group. This researcher feels that this very slight difference can be attributed to chance, so the statistics seemingly confirm the null hypothesis that there will be no significant difference in the change scores registered between male and female subjects in this study.

The most significant and interesting aspect of this study was the parallel change scores for preschoolers, kindergarteners, and first graders. Overall the preschoolers had a mean change score of $27.89 \%$, kindergarteners had a mean change score of $16.23 \%$, and first graders had a mean change score of $11.35 \%$. In the experimental group the mean change scores were $39.5 \%, 19.32 \%$, and $13.78 \%$ respectively. In the control group, the mean change scores were $15.39 \%, 8.62 \%$, and $1.37 \%$ respectively. These scores indicate that all age groups did have higher change scores when puppets were used as the instructional medium, but they also 
call for analysis of the symmetrical pattern represented by all three sets of scores.

Why did preschoolers have higher change scores than kindergarten children, and why did kindergarten children have higher change scores than first graders?

The first avenue of speculation was that preschoolers had less base knowledge of the selected nutritional concepts that were presented, therefore they had lower pretest scores and a greater area for growth. Consequently, low pretest scores would presuppose to a higher change score. In this study, the statistics at the onset seemingly substantiated that supposition. The mean pretest score for all preschoolers in the study was $52.81 \%$. Their mean change score was $27.89 \%$. The mean pretest score for the kindergarten children was $63.73 \%$ and their mean change score was $16.23 \%$. The pretest mean for first graders was $78.83 \%$ and the mean change score for them was $11.35 \%$. In the overall study then, the comparison of pretest and change scores would seem to support the supposition that because the younger subjects had less base knowledge, they attained greater growth.

In the experimental group, the supposition also held. Preschoolers had a mean pretest score of $52.79 \%$ and they attained a mean gain of 39.5\%. Investigating the individual scores, the child having the lowest pretest score, 24\%, had a gain slightly higher than the mean gain for the group. 
He reached a score of $67 \%$ for a $43 \%$ gain, but the next to the lowest pretest score was $30 \%$ and that child's score jumped to 100\%. However, most of the children with the lower pretest scores in the experimental group had the higher change scores. The pattern held throughout the kindergarten and first grade experimental groups.

However, an inconsistency developed in the control statistics. The change scores followed the pattern, but the kindergarteners had a slightly lower pretest score, $51.76 \%$, than the preschoolers, 53.92\%, yet the preschoolers had the higher change scores and the symmetrical pattern of preschool greatest, kindergarten next, and first graders least, remained.

In the analysis of the individual preschooler's test scores in the control group, there was no consistency in lower pretest.scores leading to higher change scores. A child with the lowest pretest score of $34 \%$ moved up only $6 \%$, while one with a pretest score of $42 \%$ moved to $82 \%$ on the posttest. There was also no consistency in the pattern among the individual kindergarten children. The lowest pretest score was $19 \%$ and that child's posttest score was $9 \%$, a drop of $10 \%$. The next lowest pretest score in this group was $31 \%$. One child who had this score gained $36 \%$ while another dropped 15\%. There was also no pattern whatsoever evident among the first graders in the control group. 
In the comparison of change scores for all experimental and control subjects, the corollary of low pretest to high gain scores also did not hold. The pretest mean for the experimental group was $71.06 \%$ and the mean change score was $18.53 \%$. The mean pretest score for the control group was $64.36 \%$. The mean change score was $7.95 \%$. A lower pretest score did not always produce a higher change score. The supposition therefore that lower pretest scores presuppose to higher change scores might have some validity, but it cannot stand by itself. There must be other factors why preschoolers attained higher change scores than kindergarteners and first graders.

This researcher contends that a very important factor in the younger child's attainment of higher gain scores is that the younger the child, the greater his ability to enter the realm of fantasy. The world of make-believe is the real world to the preschooler. He often does not differentiate between the two. Early childhood educators, including Piaget, contend that during the preschool age period, symbolic play is at its peak. Imaginary characters become interiorized, or a part of the child. Also, in these years, there is an increasing attention to detail. ${ }^{4}$ This theory then can possibly give us an insight into why preschoolers had the highest percentage of gain. They identified with the puppets to a higher degree than did the kindergarteners and first graders. The puppet story was 
not make-believe, it was real, and because of the preschooler's attention to detail, they were able to recall the concepts. Evidence of this was observed by the investigator at the Helen Gordon Child Development Center. When the investigator had finished each posttest interview with the preschoolers, she let each child play with the Granny Goody puppet. Wanting to see what each could do, the investigator impersonated Jody and the child played Granny. All of the children repeated many of Granny's exact words. Three of the 14 went through the script almost verbatim. All of the children admonished Jody for not eating his breakfast and told him that was why he had no energy. Most of them did not even know what the word energy meant prior to the story.

In regard to the parallelism of the scores for the control group, the preschoolers probably viewed the investigator's acting as symbolic play, therefore they were also able to identify with her to a greater degree than could the kindergarten and first grade children. This could have been the reason for higher change scores.

Early childhood educators say that by age seven, children have moved out of the realm of fantasy. 5 Since it is a gradual movement, this researcher believes that this is one possible explanation for the parallelism of the change scores and why preschoolers attained higher change 
scores, kindergarteners second highest, and first graders the lowest change scores.

From years of experience in teaching, this researcher also realizes that attention spans of children vary. The story. was possibly a little too long to hold the attention of all children. This could have accounted for the unpredictability and nonpattern of the change scores in the control group. Another factor, which could also have adversely affected the change scores of the kindergarten and first graders in the control group, was the fact that the research was carried out too close to the end of the school year. This researcher realizes that attention begins to wane when vacation is near. This could have been a very important factor. Since there were no zero or negative scores in any other groups, not even the control preschool group, something other than the story is suspect. Another factor could be the classroom teacher's attitude. Since it was the end of the year, the teacher in the kindergarten control classroom had a preconceived or predetermined attitude toward her class. She told me they were nonlisteners. Educators know that children often produce what is expected of them. Since it was so late in the school year, possibly they had been conditioned not to listen. On the other hand the first graders acted attentive, but had lower scores, so another factor such as that the story was out of the realm of fantasy seems to be a 
more logical explainer for their low scores. Research provides evidence that by the age seven, children are usually beyond the realm of fantasy. ${ }^{6}$ As it was the end of the year, most first graders would be seven years old or older. But whatever the reasons, the null hypothesis that there will be no difference among the change scores of preschool, kindergarten, and first grade students in this study and the null hypothesis that there will be no significant difference in the mean change scores among preschool, kindergarten, and first grade students as a result of treatment (puppet storytelling or dramatic storytelling) in this study must be rejected. 


\section{Chapter 4--Notes}

${ }^{1}$ Betty Pollus, "Using 'Wheeler' to Mainstream," Puppetry in Education News (January 1979), p. 8-9.

${ }^{2}$ Richard Warren Trullinger, "Differential Measurement of a Language Concept Presented Via Videotape Playback to First Grade Students" (M.S. thesis, Portland State University, 1974), p. 1 .

3 Jacques C. Chicoineau, "The Use of Puppetry in the Teaching of Foreign Language," in Current Approaches to the Teaching of Foreign Language, by Martin T. Barrett, Midwest Modern Language Association (October 1972 ).

${ }^{4}$ Mary Ann Spencer Pulaski, Understanding Piaget (New York: Harper Row, 1971), p. 96-117.

5 Ibid. $6^{6}$ Ibid. 


\section{CHAPTER V \\ SUMMARY AND IMPLICATIONS}

SUMMARY

Puppetry has been in existence since prehistoric times and has been used as an educative and communicative media since its inception. Historians were aware of its use, but American educators gave it little thought until "Sesame Street" and "The Muppets" made their debut. Since that time a large amount of anecdotal literature describing various uses of educational puppetry has surfaced, and the reporters of these anecdotes attest to the educational benefits which can be derived from the use of puppetry. Only a few empirical studies were found by this researcher. Those that were found supported the claim that puppets are a valuable educative medium. Because there was so little empirical data available, this researcher decided that she would like to, in some small way, empirically assess the value of puppets.

The study tested the null hypothesis: There will be no significant difference in increase in knowledge of selected nutritional concepts for preschool, kindergarten, and first grade students when puppets are used as the 
instructional medium than when dramatic storytelling is used as the instructional medium.

A pretest, posttest design was employed and a story was presented by way of dramatic storytelling and puppet storytelling. One hundred fifty-four subjects were used in this study. There were 112 in the experimental group and 42 in the control group. In the experimental group, where puppets were used as the educative medium, the students had a mean change score of $18.53 \%$. This was $11.58 \%$ higher than the control group's mean change score of 7.95\%. Therefore, this hypothesis was rejected.

The study also tested the null hypothesis that there would be no significant difference in mean change scores registered by male and female subjects. There were 82 males and 72 females as subjects in this study. In the total study, male subjects had a $2.13 \%$ higher mean change than female subjects. In the experimental portion, male subjects had a higher mean change score of only $3.46 \%$, while in the control portion of the experiment, females had a higher mean change score of $2.86 \%$. This researcher attributed this slight variation to chance and therefore accepted the null hypothesis that there would be no significant difference in the mean change scores between male and female subjects in this study.

A third and fourth hypothesis were also tested. They essentially were: There will be no significant difference 
in the mean change scores among preschool, kindergarten, and first grade students in this study, and there will be no significant difference in the mean change scores among preschool, kindergarten, and first grade students as a result of treatment in this study. These hypotheses were rejected.

Of interest to this researcher was the proportional pattern of highest change scores for preschoolers, second highest for kindergarten children, and lowest change scores for first graders which existed throughout the study. In the total study mean change scores were as follows: preschoolers, 39.5\%; kindergarteners, 19.32\%; and first graders, $13.78 \%$. In the control group the pattern was preschoolers, 15.39\%; kindergarteners, $8.62 \%$; and first graders, $1.37 \%$.

These statistics indicate three things to this researcher: (1) that the increase in knowledge of selected nutritional concepts in this study was higher when puppets were used as the educative medium, (2) that there must have been a reason why preschoolers had the highest mean change scores, and (3) that there must have been another factor operating to produce the symmetrical change score pattern among the preschool, kindergarten, and first grade groups. This researcher found the correlation of low pretest scores to be significant at the $p<.001$ level, so she speculated that the younger children had less base knowledge 
of nutritional concepts, therefore they had more to learn, so their change scores would be higher. The comparison of all pretest and change scores and the comparison of pretest scores and change scores in the experimental group supported this supposition.

However, an inconsistency was found in the relationship of the control group's pretest scores and their change scores. The inconsistency called for further analysis. That analysis revealed another important factor which could account for the pattern of the change scores. It was that the younger the child, the greater his ability to enter the realm of fantasy. The world of make-believe is the real world to the preschooler, and he often does not differentiate between the two. This tendency to makebelieve is at its peak in the preschool years. Preschoolers identify with puppets, so when the puppet learns, the child who has identified with the puppet also learns. This researcher believes that this, then, could have been a very important factor in the pattern of preschoolers' highest change scores, kindergarteners' second highest, and first graders' lowest change scores. It is evident that there is a great deal of room for further research in this area.

\section{IMPIICATIONS}

As the findings of this study demonstrate that puppets do facilitate learning, it is hoped that these findings will 
influence more teachers to experiment with puppetry in their classrooms. It is also hoped that this study will generate further empirical research in the area of educational puppetry.

The results of this study suggest further research in the same area using different factors and approaches. They include the following:

1. Using equal numbers of preschool, kindergarten, and first grade children to see if the pattern would appear the same when equal numbers were used, although this researcher has no reason to believe that this affected the study.

2. Using equal numbers of subjects in the experimental and control groups, although this researcher feels that this was not an influencing factor in the outcome of the study.

3. Doing the entire study earlier in the school year. This researcher feels that this could have an important bearing on results, because of base nutritional knowledge and maturity.

4. Facilitating the control and the experimental treatments on the same day, in the same school, in the same environment, rather than a month apart in separate schools. These might or might not affect the outcome.

5. Using subject matter where base knowledge is closer to zero for all groups, so as to gain a truer picture for change scores. 
6. Using a shorter story, so that attention span would not be a negative factor.

7. Using another comparative method to see what effect it would have on change scores.

8. Investigating in greater detail the cause for the correlative scores of $P>\mathbb{K}>1$, and investigating these to see if this would hold true when other subject matter was used.

9. Investigating the implications of the child's ability to gain more from puppets, because of his ability to enter the realm of fantasy.

The results of the present study suggest that: preschool, kindergarten, and first grade students will have a greater increase in knowledge of selected nutritional concepts as a result of viewing a puppet story than a similar composite of student will have when the same material is presented via dramatic storytelling, change scores will be significantly different among preschool, kindergarten, and first grade student's, and treatment (puppet storytelling versus dramatic storytelling) will cause significant differences in the change scores among preschool, kindergarten, and first grade children, and that there will be no significant difference between change scores of male and female subjects in regard to the questions asked in this study. 
Educators are constantly searching for ways to make education meaningful. Puppetry surely holds some answers. Teachers who have used puppets are delighted with the results and the present study lends support to the thesis that when puppets are used in the classroom learning is facilitated.

Fads and trends come and go. Whether it is "Back to Basics," "Talented and Gifted," or "Mainstreaming," they all have one objective. It is to provide an education suitable to the individual child. This researcher feels puppets can be a very valuable tool in this important endeavor. 


\section{BIBLIOGRAPHY}

Anderson, Iinda. "A Travelling Handicapped Troupe," Puppetry in Education News (May-June 1979).

Arnott, Peter. Plays Without People: Bloomington, Indiana: University of Indiana Press, 1964.

Baird, Bil. The Art of the Puppet. New York: Macmillan Co., 1965. tion Inc.

Ball, S. and Bogatz, G. "The First Year of Sesame Street; an Evaluation." Princeton, New Jersey: Educational Testing Service, 1970.

Burn, Jean Reges. "Improving the Self Concept of the Exceptional Chila," Puppetry Journal (Sept.-Oct. 1978).

Chesse, Bruce. "Puppetry in Education," Puppetry Journal

Chicoineau, Jacques C. "The Use of Puppetry in the Teaching of Foreign Language," in Current Approaches to the Teaching of Foreign Language, by Martin T. Barrett. Midwest Modern Language Association, Oct. 1972.

Currell, David. Puppetry for School Children. Newton, Mass.: T. Branford Co., 1970.

Delano, Dorothy. "Workshop: Defining Student Speech Problems," School Management (Feb. 1967).

Dinham, Sarah M. Exploring Statistics: An Introduction for Psychology and Education. California: Brooks Cole Publishing Co:, 1976.

Dunhill, Joanne. "The Diagnostic Potential of Puppets," in Puppets in Therapy. Edited by A. R. Philpott. Boston: Plays Inc., 1977.

Engle, Murray: "Puppets Add Zest to Children's Study of Energy," Puppetry Journal (July-August 1974). 
Evertts, Eldonna, Hunt, Lyman C., and Weiss, Bernard J. About Me. New York: Holt, Rinehart and Winston Inc., 1973.

Food: Your Choice, Level 1. Kit. Illinois: National Dairy Council, 1977.

Gardner, Rob. "Puppetry Speaks a Universal Language," Puppetry Journal (Jan.-Feb. 1976).

Gordon, Margaret S. "Puppetry in Speech Clinics," Puppet Post (Spring 1953).

Hook, Patricia. "Creative Math with Puppets," Puppetry Journal (Jan.-Feb. 1976).

Inverarity, Robert Bruce. The Art of the Northwest Coast Indians. 2nd ed. Berkeley, California: University of California Press, 1967.

Johnson, Victoria S. "Bringing Books Alive Through Puppets," Elementary English (October 1966).

Kharasch, Ethel. "Puppets as Educative Media," Elementary English (1972).

Koenig, Lois and Weisholz, Leila. "Puppets and Poetry," Puppetry in Education News (May 1978).

Kohrs, Charlotte. Puppets in Phonics and Reading. San Diego: Creative Children's Press, 1976.

Malkin, Michael R. "The Pleasures of Puppets and Poetry," Teacher (October 1974).

Marcus, Simone. "Therapeutic Puppetry," Puppet Post
(Summer i948).

Maurer, Carolyn G. "of puppets, feelings, and children," Elementary School Guidance and Counseling (October 1977).

Obraztsov, Sergei. The Chinese Puppet Theatre. Cited in The Art of the Puppet by Bil Baird. New York: Macmillan Co., 1965.

Ostrow, May B. and Taylor, Debra. "Why a Puppet," Puppetry in Compensatory Education. Sanford, Florida: Seminole County Board of Public Instruction, 1973. 
Philpott, Violet. "Puppetry and Deaf Children," in Puppets and Therapy. Edited by A. R. Philpott. Boston: Plays Inc., 1977.

Pollus, Betty. "Using 'Wheeler' to Mainstream," Puppetry in Education News (November 1977).

, Latshaw, George, and Olesker, Stuart. "Dialogue," Puppetry in Education News (January 1979).

Pulaski, Mary Ann Spencer. Understanding Piaget. New York: Harper Row, 1971.

Quisenberry, Nancy and Willis, Margo. "Puppets as Learning Tools," Language Arts (Śpt. 1975).

Reich, R. "Puppetry--a Language Tool," Exceptional Child (April 1968).

Renfro, Nancy. "An Enlightening Experience: Learning from the Handicapped," Puppetry in Education News (January 1979).

Richmond, Julius B., Pounds, Elenore T., and Fricke, Irma B. Health and Growth 1. Illinois: Scott Foresman Co., 1971.

- Health and Growth 2. Illinois: Scott Foresman Co., 1971.

Richmond, Julius and Pounds, Elenore T. You and Your Health: School, Home and Community. Illinois: Scott Foresman Co., 1977.

Rowland, David S. "A Puppet Theatre for Language Teaching." Leeds, England: Neufield Foundation, May 1965.

Rubin, Joseph S. "Benjamin Beaver's Box," Elementary English $(1973)$.

Sheehan, Ruthmarie. "A New Vision Through Puppets," Puppetry in Education News (November 1977 ).

Simons, W. Herbert. "In Praise of Muddleheaded Anecdotalism," Western Journal of Speech Communication (Winter 1978).

Smith, Daniel M. Educational Psychology and Its Classroom Applications. Boston: Allyn \& Bacon Inc., 1978.

Sylwester, Roland. "The Puppet in the Church," Puppetry Journal (Jan.-Feb. 1972). 
Trullinger, Richard Warren. "Differential Measurement of a Language Concept Presented Via Videotape Playback to First Grade Students." M.S. thesis, Portland State University, 1974.

Vogelsang, Robert, Saubidet, Eduardo, and Sullivan, Deborah. "The Development of Positive Attitudes and Social

Values in Children Through Puppetry--or--Listen to Floyd," Puppetry Journal, forthcoming.

Williams, Elizabeth. "Helping Children Feel Like Someone Else and Talk Like Someone Else," Elementary English (January 1967). 
APPENDIX A

PRETEST OBJECTIVES, PRETEST, AND POSTTEST 


\section{PRETEST OBJECTIVES}

Objectives:

The student will be able to relate:

1. Food gives you energy.

2. You need energy to do active things.

3. You are more likely to tire easily when you don't eat your meals.

4. You need to eat food from each of the four basic food groups each day.

Questions to measure the above objectives based on the pretest order were:

$\begin{array}{ccc}\text { Page } & \text { Question } & \text { Objectives } \\ 1 & 1 & 3 \\ 1 & 2 & 3 \\ 2 & 1 & 3 \\ 2 & 2 & 2 \\ 2 & 3 & 3 \\ 3 & 1 & 1 \\ 3 & 2 & 2 \\ 3 & 3 & 2 \\ 4 & 1 & 1 \\ 4 & 2 & 4 \\ 4 & 3 & 1 \\ 5 & 1 & 4 \\ 6 & 1 & 4 \\ 7 & 1 & - \\ 7 & 2 & 4 \\ 7 & 3 & 1 \\ 7 & 4 & 3 \\ 7 & 5 & 4 \\ 7 & 5 & 4 \\ 7 & 6 & 4 \\ 8 & 7 & 2\end{array}$


PRETEST

Nonie

\section{Grode}

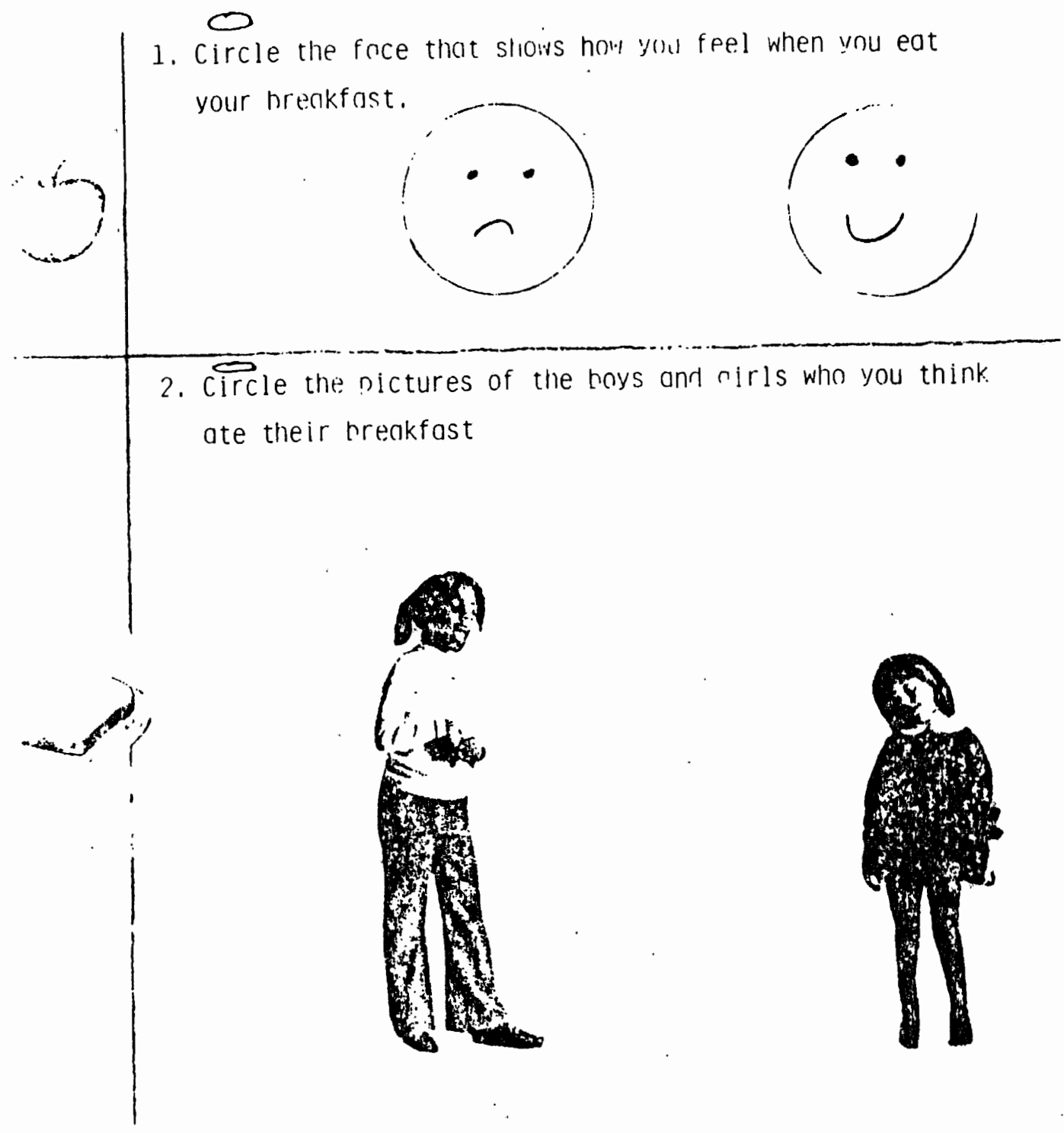



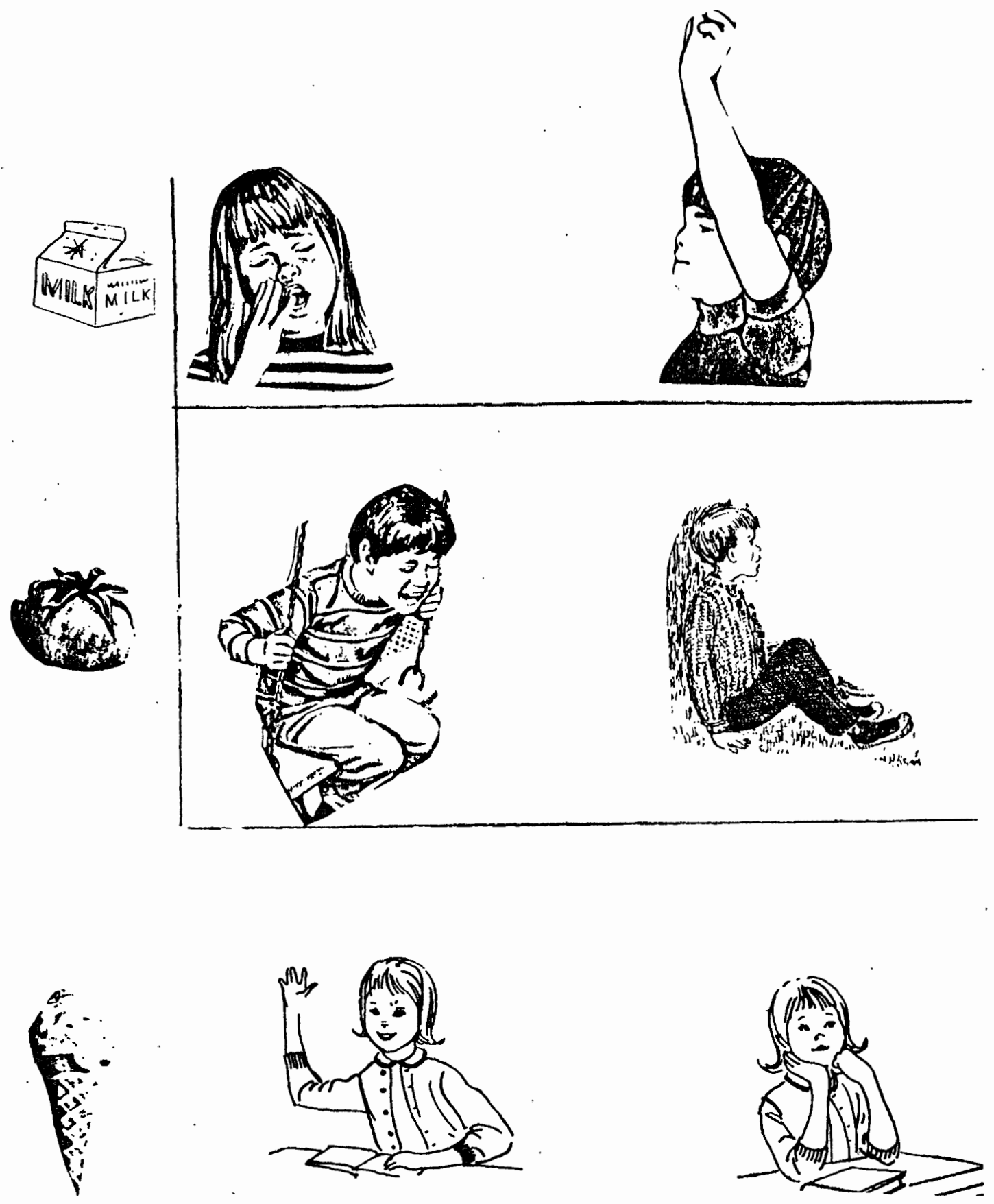

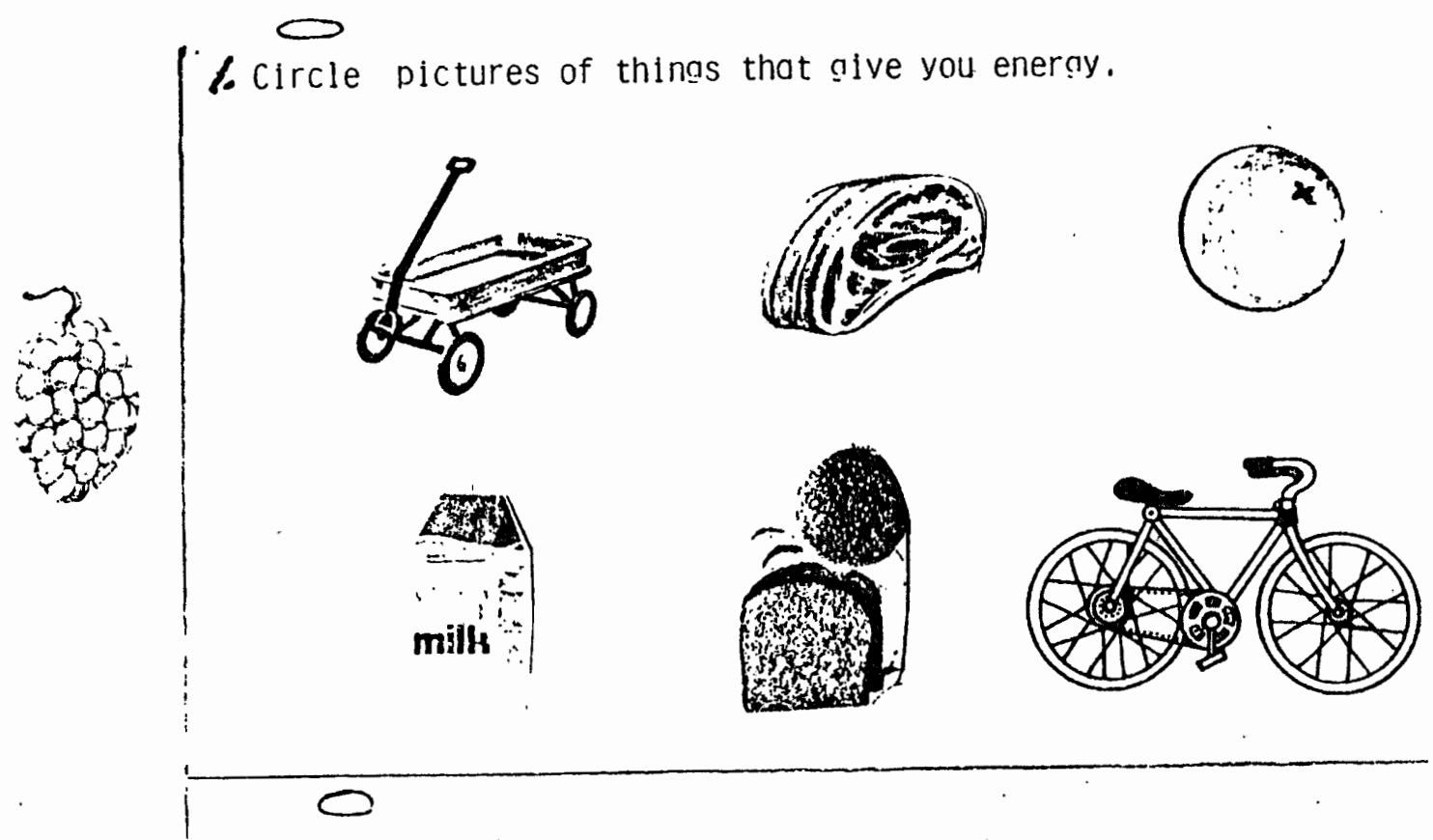

2 circle the ricture in each row that takes more eneray.
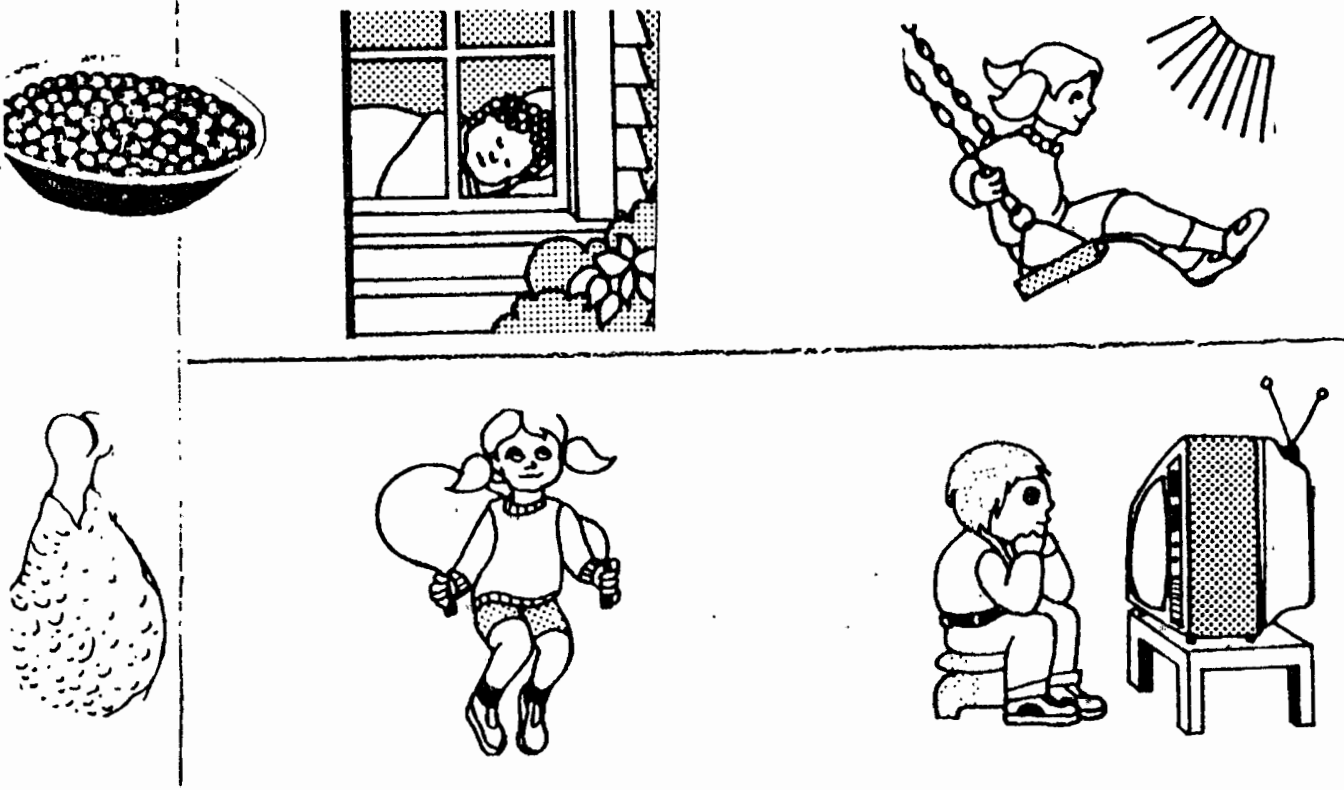


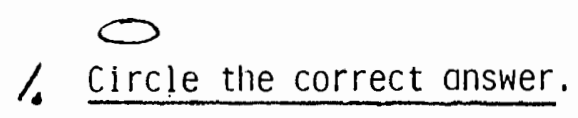

What gives you energy?

eating good food

riding a bicycle

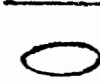

2. Circle tine good breakfast.
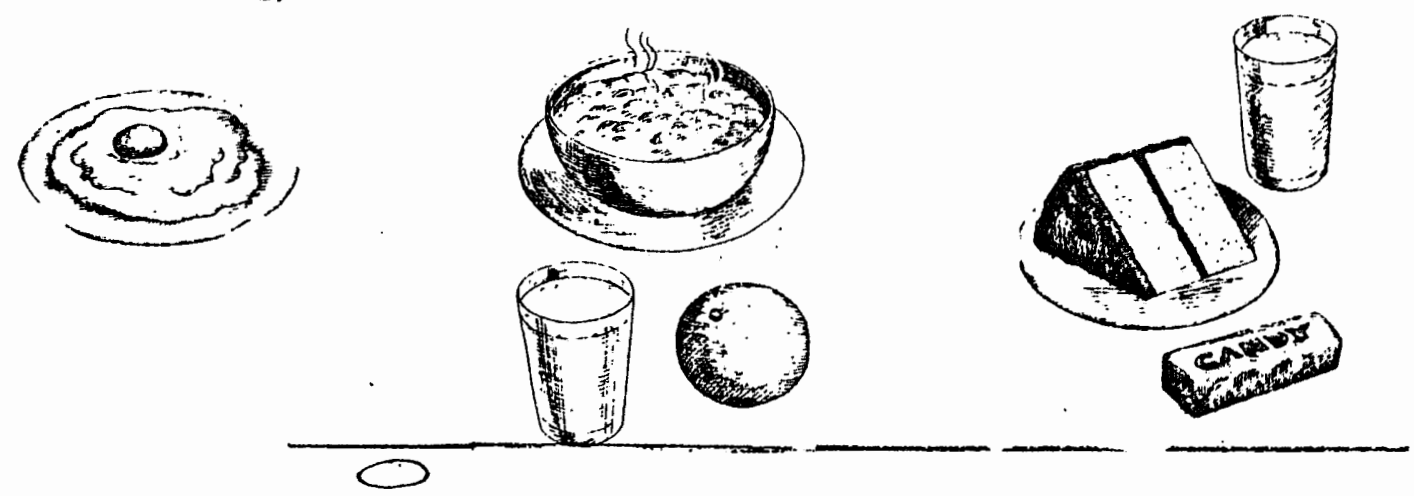

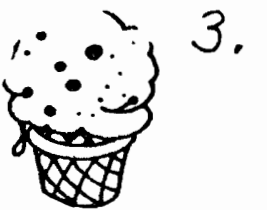

keeps ine heal thy

nukes me angry makes me tired

helps me grow

gives me enerciy 
Here are 6 sirouns of foods.

$\varnothing$

Circle the 4 groups that you need every day.
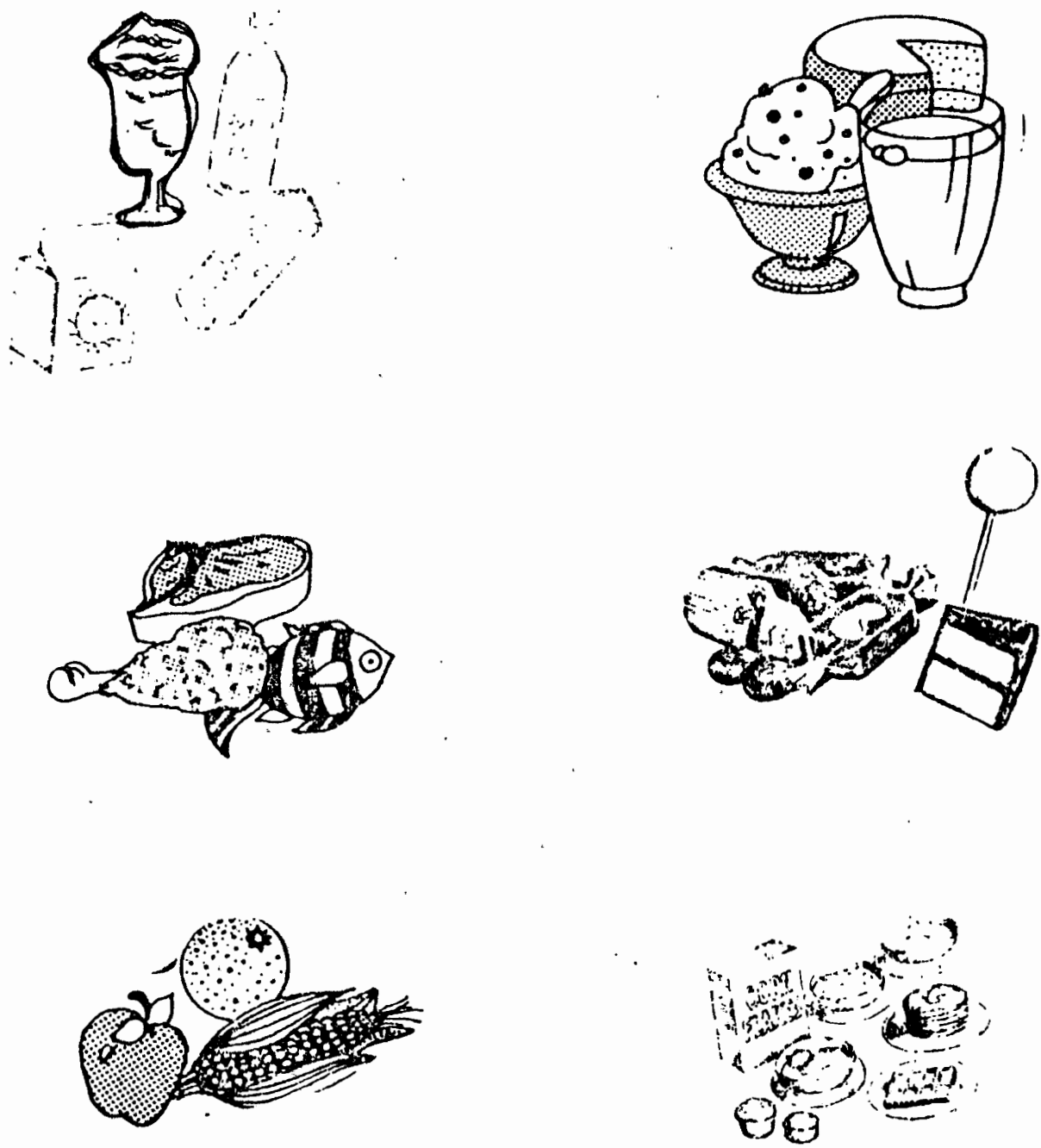


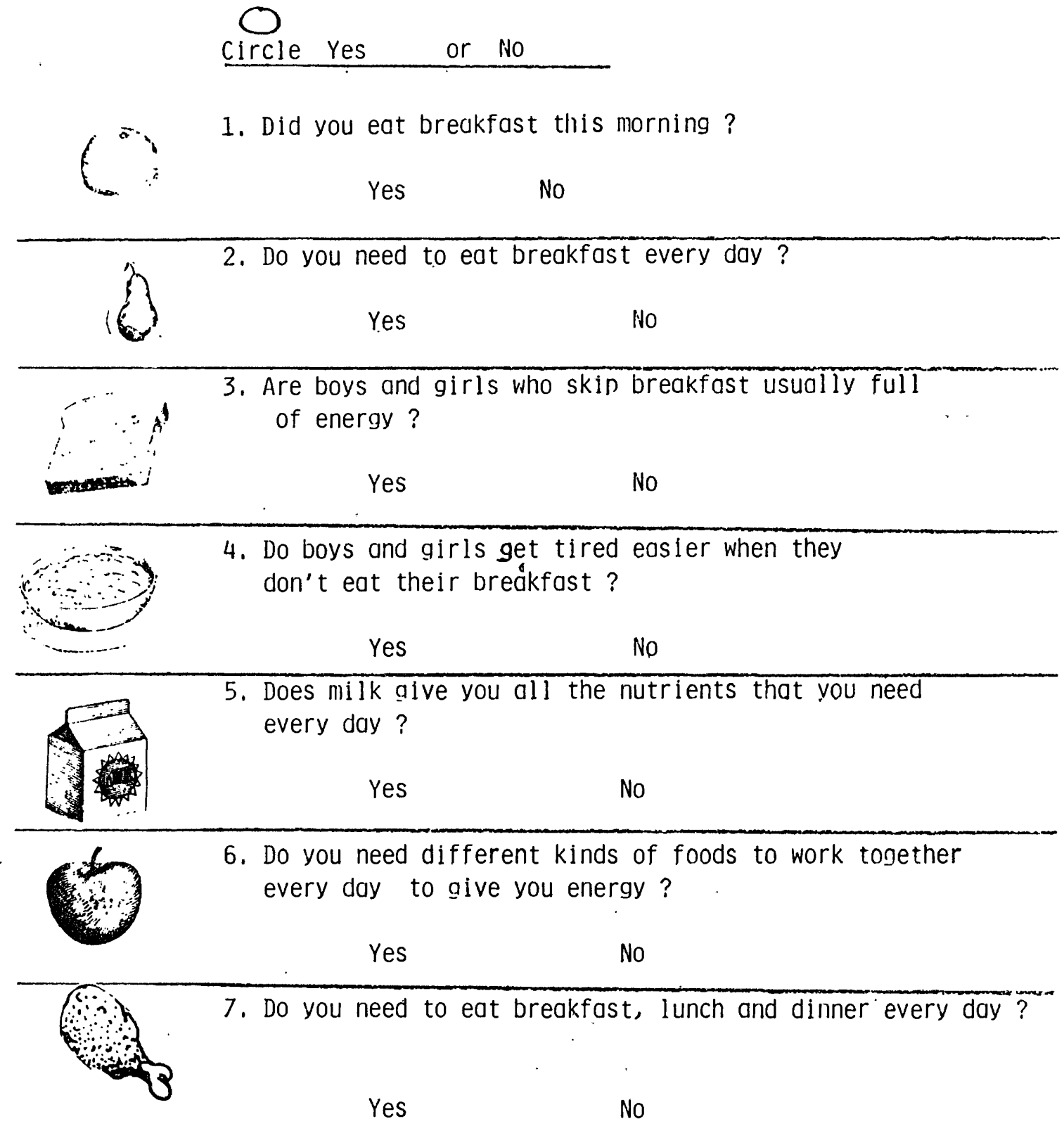


Do you know what the 4 food groups are?

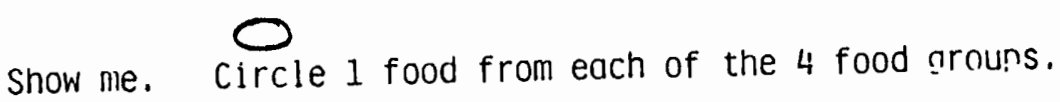
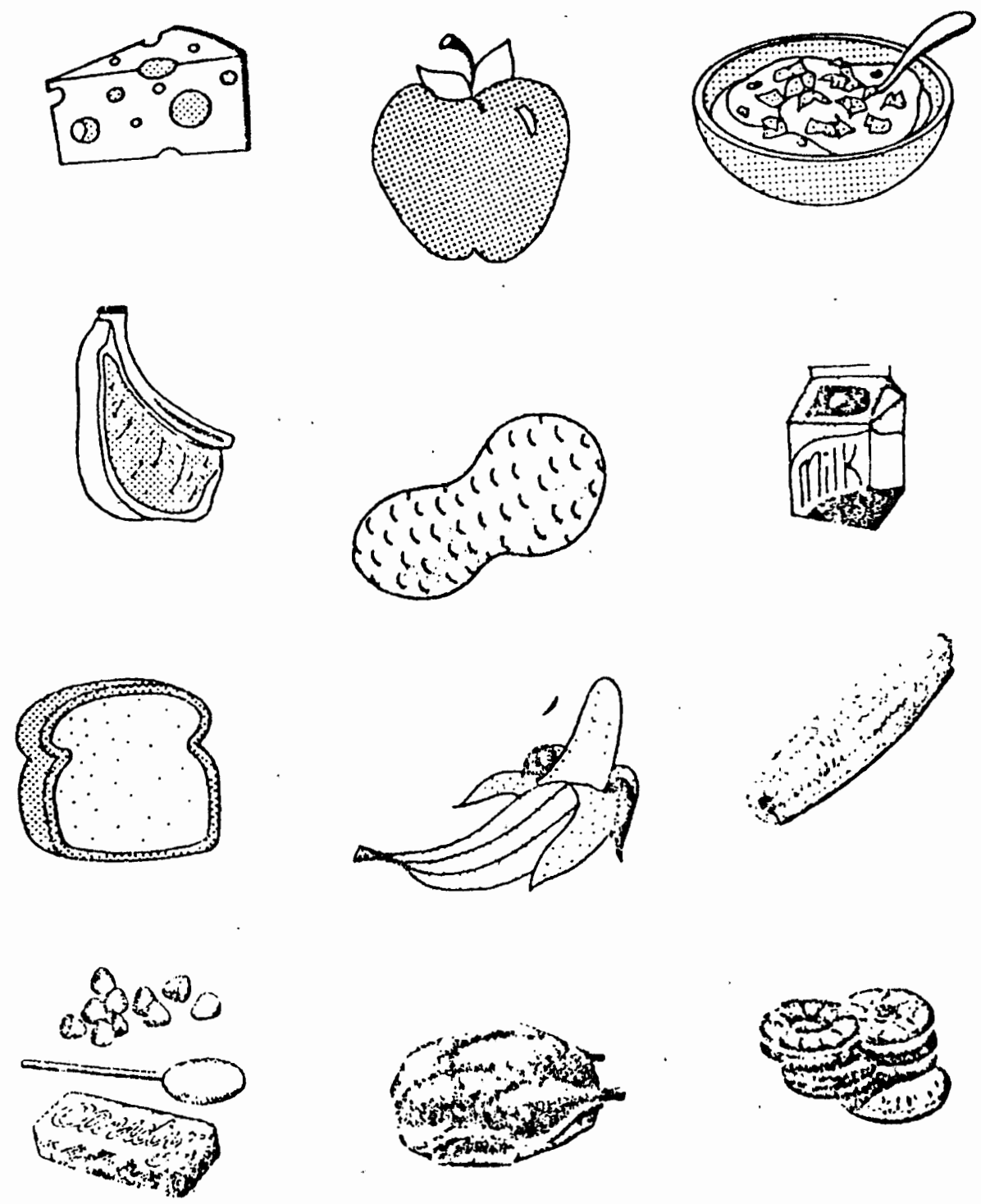
Draw a pictalle vi thre: different thines that you llke to do thut iuke enersv. 
POSTTEST

Name

Grade

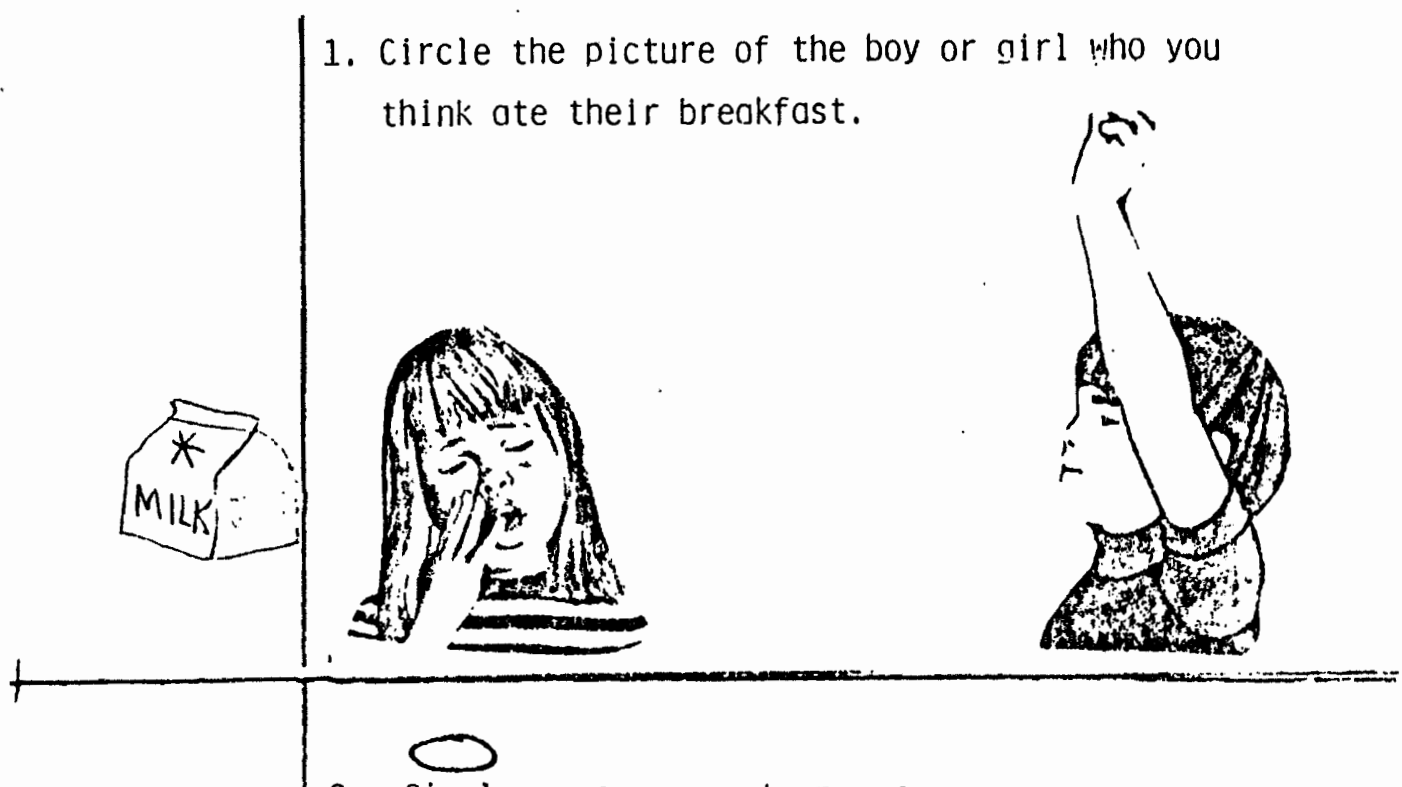

2. Circle every correct answer.

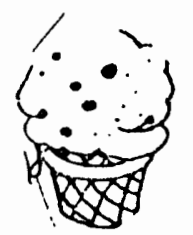

Eatinn my meals

1. helps me grow

2. makes me angry

3. gives me eneray

4. makes me tired

5. keens me heal thy 


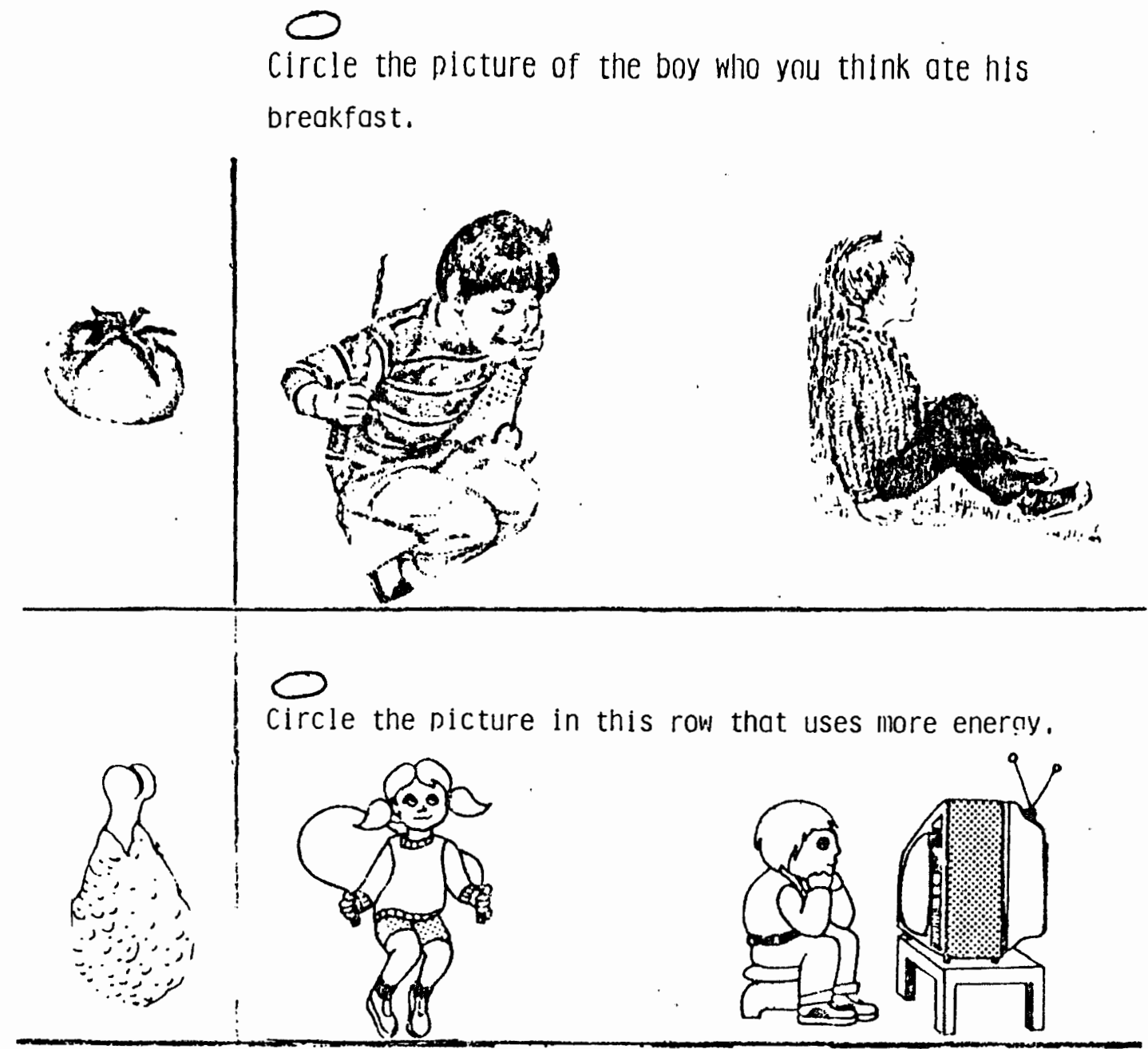

$Q$ circle the picture of the girl who you think ate her breakfast.
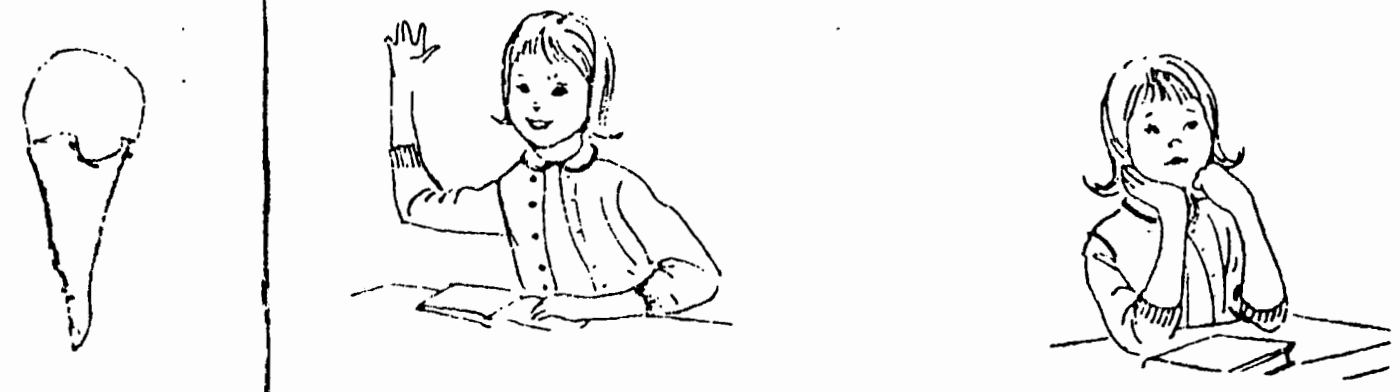
Draw a picture di thre: difterent thinss that you llke to uo thut iuke eherav. 
liere are 6 arouns of foods.

circle the 4 groups that you neted every day,
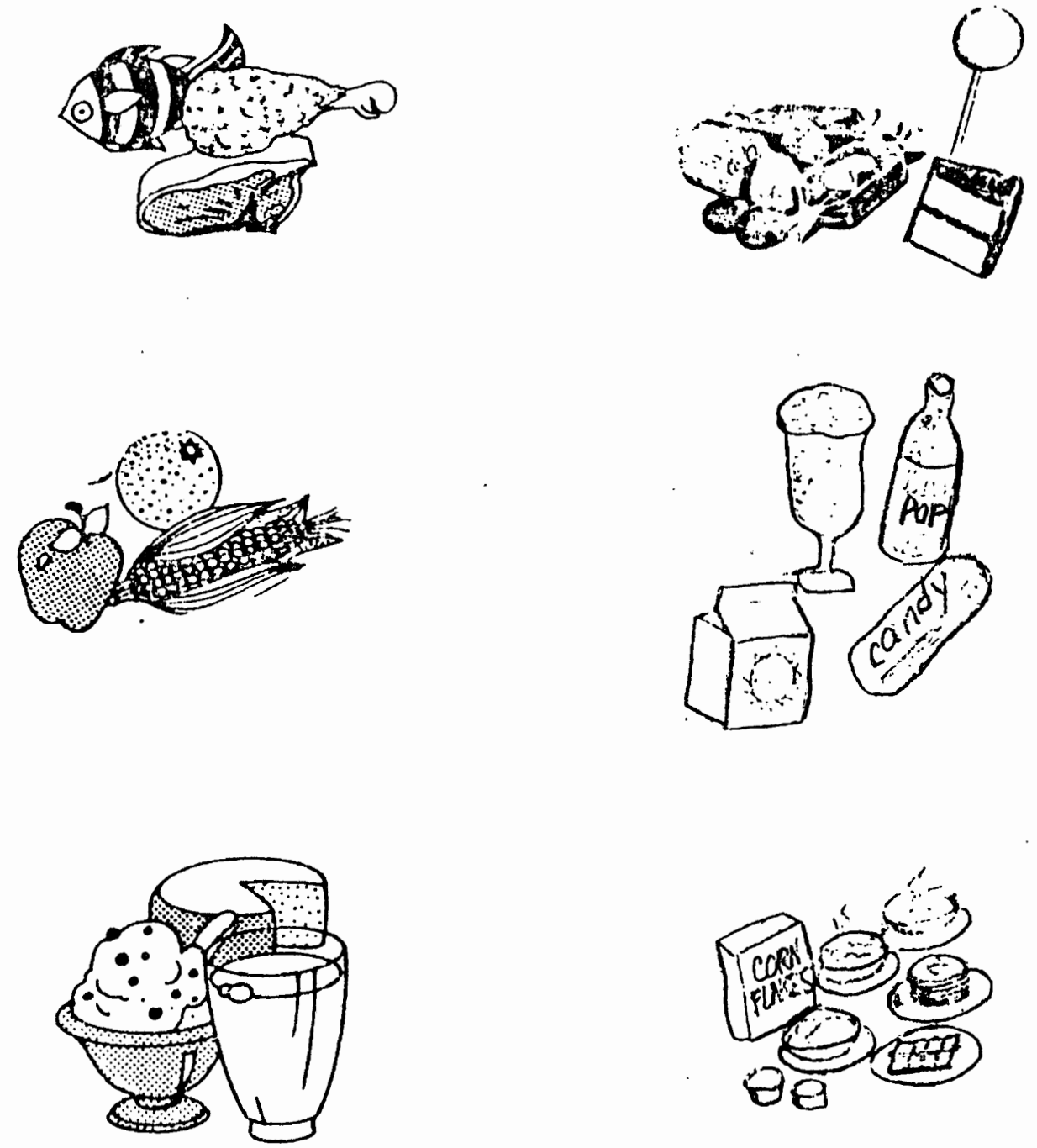
circle the ricture:

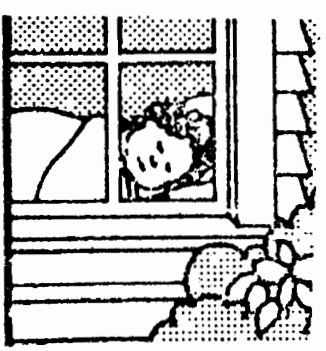

$\infty$

1. Circle the correct answer.

linot gives you enerçy ?

eating good food

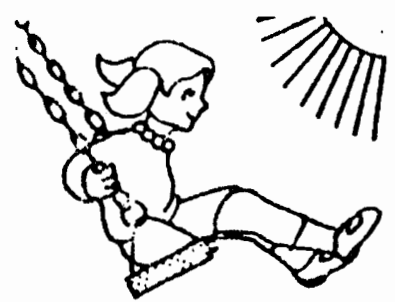

that takes more eneray.

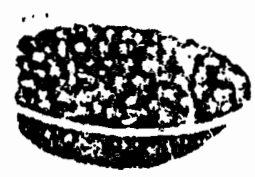

$\therefore$
0
0
0

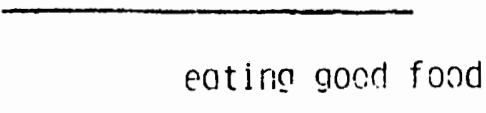

riding a bicycle

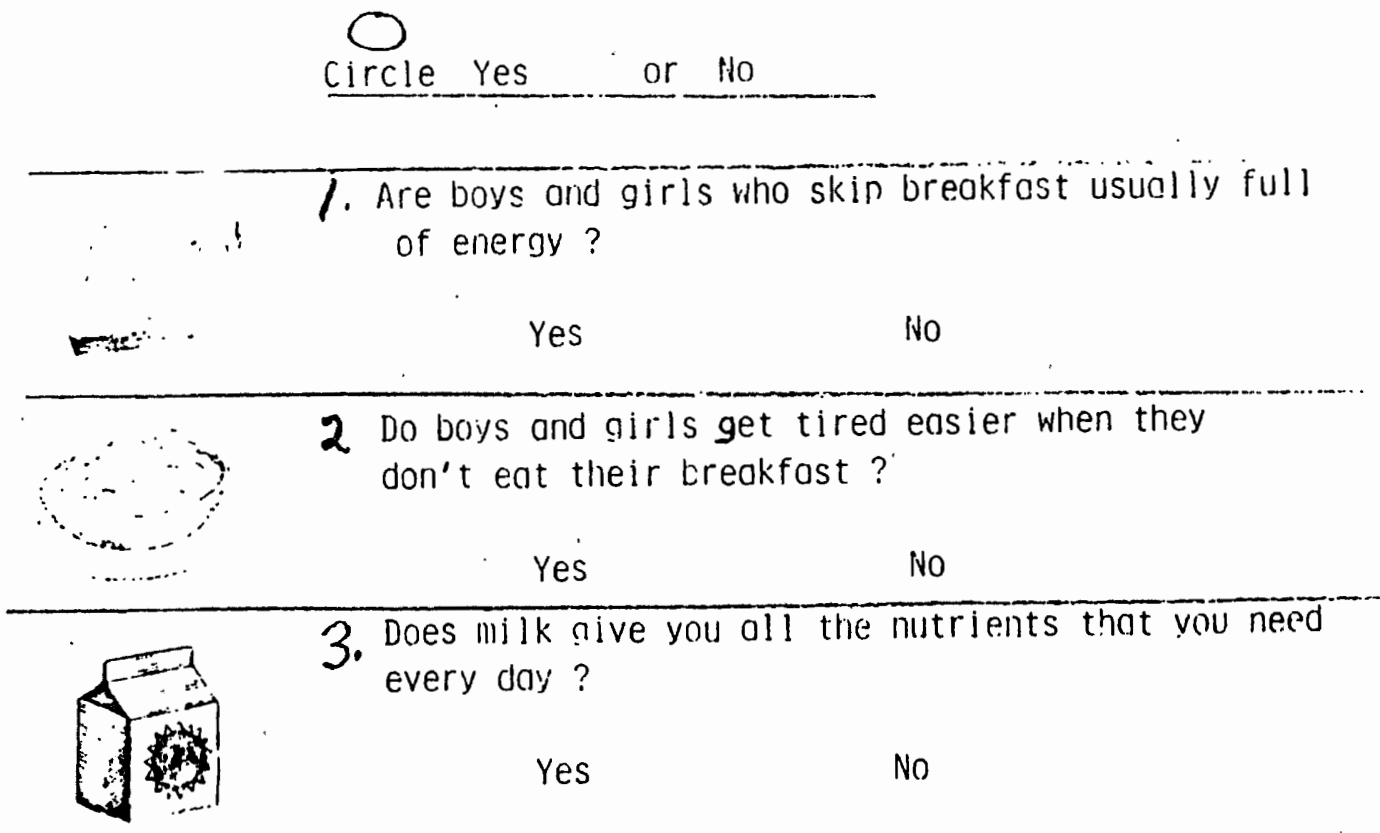




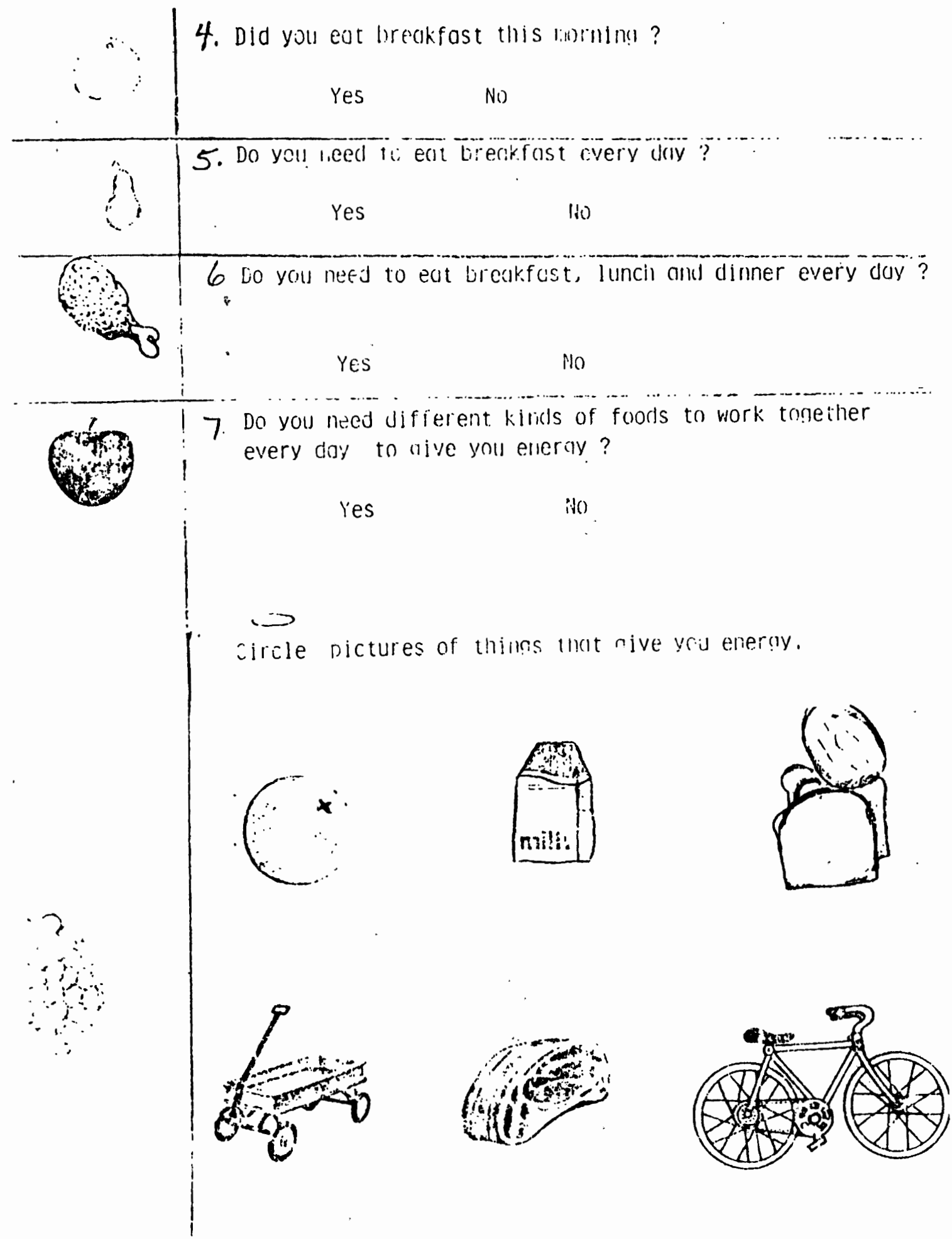




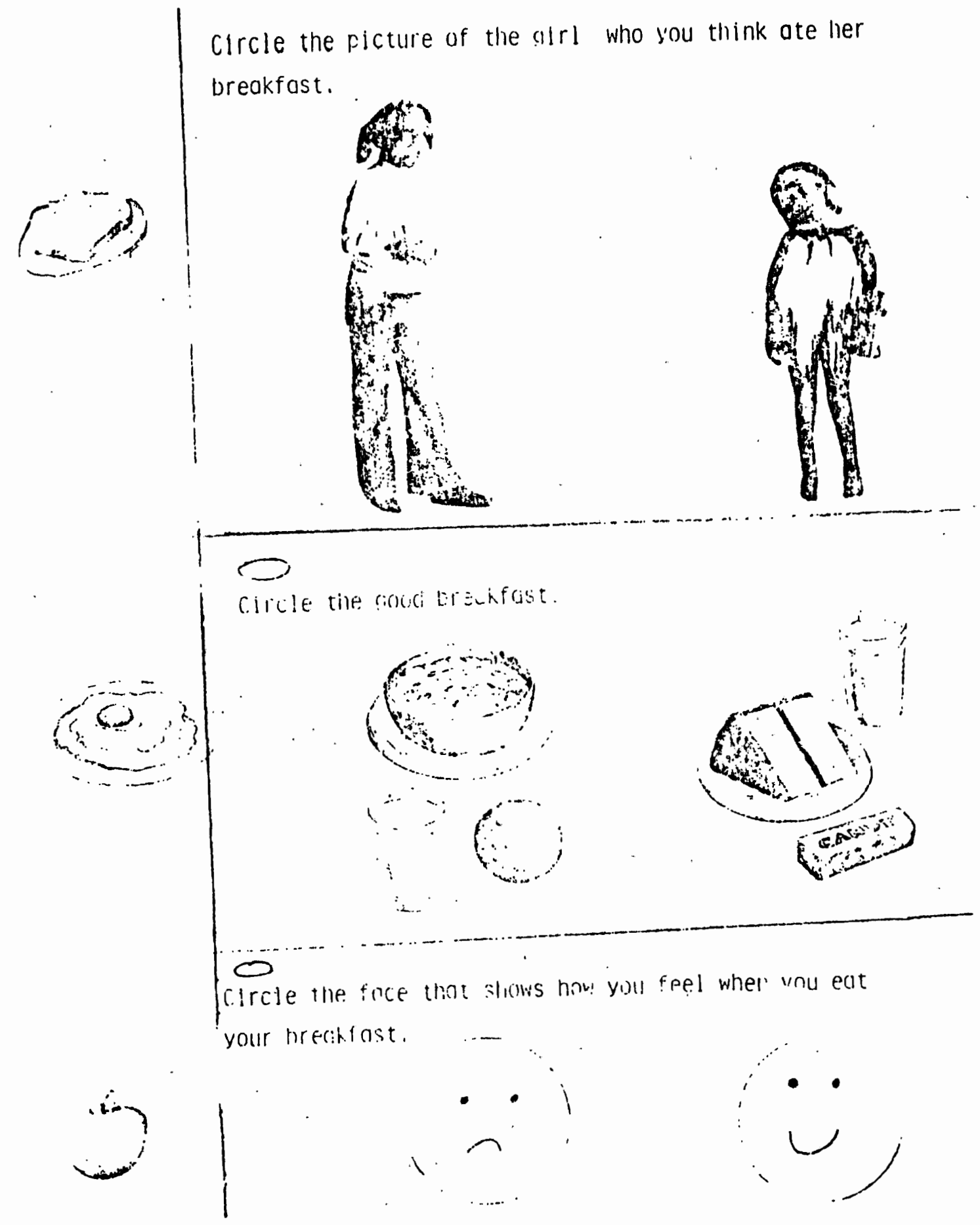


Do you know what the 4 food groups are?

\section{0}

Show me. Circle 1 food from each of the 4 food arouns.
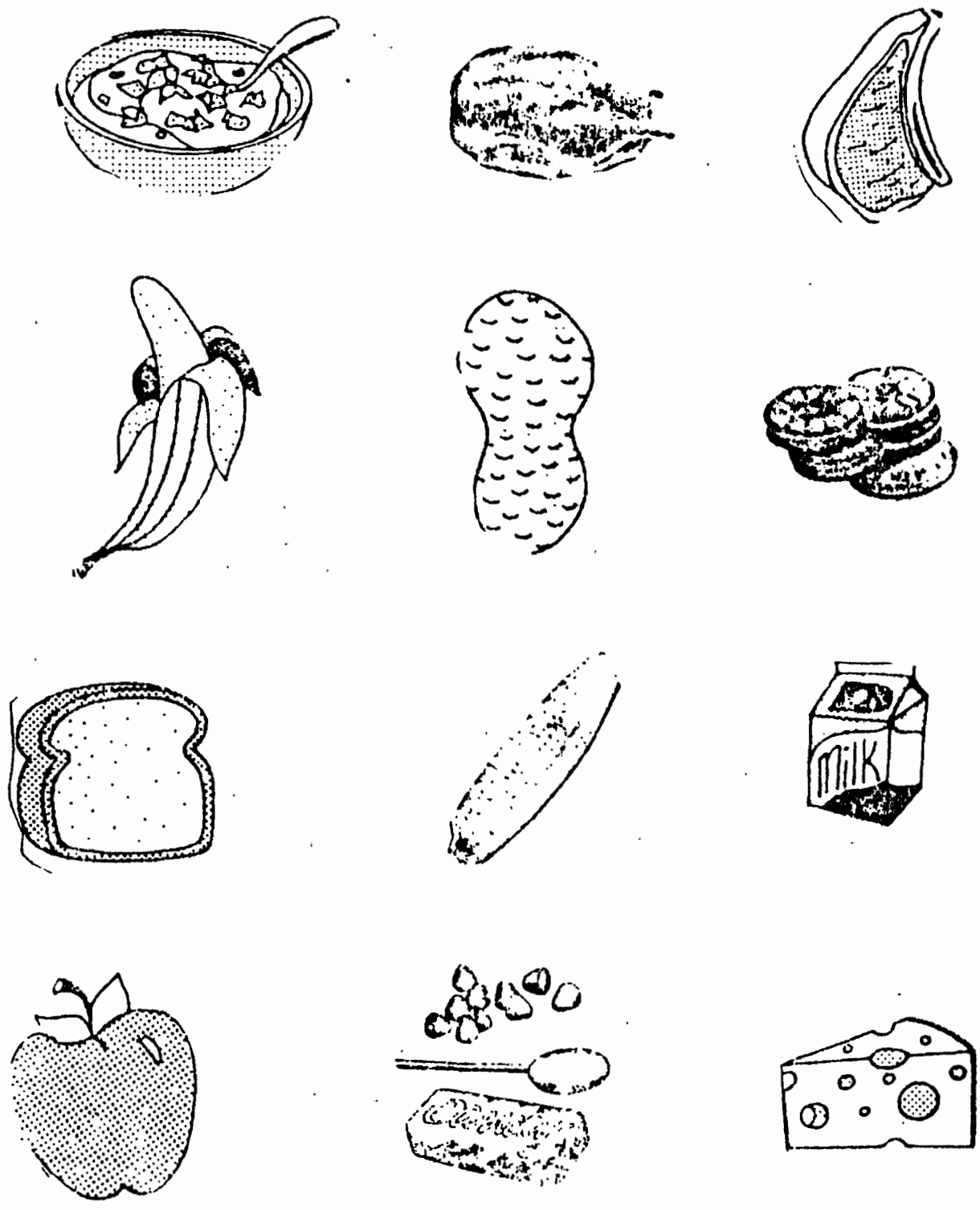
APPENDIX B

SCRIPT FOR PUPPET STORYTELIING, AND

SCRIPT FOR DRAMATIC STORYTELIING 
SCRIPT FOR PUPPET STORYTELLING

\section{Granny Goody's Magic Food Pot}

Granny: Hello, Boys and Girls. (Knock)

Boys and girls, do you hear something? I wonder who's here? Why Jody, what are you doing here?

Jody: Nothin'.

Granny: Oh yes there is, you can't fool Granny. Did someone hurt you?

Jody: No.

Granny: Come now, (pat on shoulder) tell Granny why you are here, and what the problem is.

Jody: I'm just tired.

Granny: Tired, (looks at clock) at nine o'clock in the morning? (Surprised) Nine o'clock in the morning! Boys and girls, shouldn't Jody be in school? Why aren't you in school, Jody?

Jody: Well, I was on my way, but I saw your house and I was tired, so I thought I'd stop and rest a minute.

Granny: Rest? You should have lots of pep and energy right after breakfast, shouldn't he, boys and girls? Or didn't you eat breakfast?

Jody: Well, a--a--, I just wasn't hungry. Granny: Isn't that terrible, boys and girls? That's why you're so tired. Growing boys and girls need to 
eat a good breakfast, don't they?

Jody: Aw shucks, what's so special about breakfast?

Granny: What's so special about breakfast? You sit right down, and Granny'll tell you what's so special.

Jody: I'd rather hear a story. Boys and girls wouldn't you rather hear a story?

Granny: Well, then I'll tell you a story. . Hmm, I know, I'll tell you about the Land of Energy. A long time ago in the Land of Energy, there were boys and girls who could run, and jump, and play all day and never get tired.

Jody: Never?

Granny: Mmhuh, at night when their parents tucked them into bed, the children were still full of energy and would beg for just one more story. Mothers and dads couldn't figure out why the children had so much energy, and would say to each other, "Tommy should be tired. He's played so hard today, but he's still so full of energy." Well, the children had a secret.

Jody: A secret? Boys and girls, did she say a secret?

Granny: Yes, a secret. The children had found a magic food pot, just full of healthy foods and every morning, you know what they'd do? They'd eat out of this magic food pot.

Jody: Magic food pot, outa sight! 
Granny: Then one day a bad old Wizard came along and stole the magic food pot and hid it where the boys and girls couldn't find it and they had no healthy foods.

Jody: Did he really? Oh, what a mean Wizard. Wasn't he a mean old Wizard, boys and girls?

Granny: Without their healthy foods every day, they soon became very tired. They couldn't run or jump, and they just wanted to sit around all day.

Jody: Just like me, huh Granny!

Granny: Right, just like Jody--right, boys and girls. Then, one day a farmer was digging around and found an old iron pot, and he just threw it over the fence in his field. And what do you think happened?

Jody: What?

Granny: Wanna guess?

Jody: A---

Granny: Suddenly a magic tree popped out of the ground. It had all sorts of good food on it. He knew he had just thrown an old iron pot away, but what did that have to do with this tree?

Jody: I know, Granny. I'll bet it was the magic food pot that the bad old Wizard stole!

Granny: You're right!. The farmercalled all of his friends together to get some of the food and they were filled with energy. But they were all puzzled. . (rubs head) 
Jody: Hmm.

Granny: Until an old, old grandpa remembered the magic food pot that he had eaten out of every morning when he was a little boy.

Jody: They found the magic food pot! I bet that fooled that old Wizard.

Granny: Yes, that's right. And the Wizard lost, because the healthy foods were stronger magic than the Wizard's.

Jody: I wish I could find that magic food pot and have some of those healthy foods. Maybe then I wouldn't. be so tired.

Granny: I think you can. Jody: Really!

Granny: That magic food pot is in my kitchen and in your kitchen, and in yours too, boys and girls.

Jody: How come I've never seen it?

Granny: You've seen it! You just didn't recognize it. Do you know what healthy foods are?

Jody: Huh, uh. . boys and girls do you?

Granny: Do you know what foods you need every day to give you energy and help you grow strong and healthy?

Jody: Uh, uh. - apple and milk and--(pause)

Granny: Well, those are two, but there are lots of other good healthy foods. Every day you need fruits and vegetables. 
Jody: Fruits and vegetables.

Granny: Meat.

Jody: Meat.

Granny: Milk.

Jody: Milk.

Granny: Or something made out of milk and something made out of grain.

Jody: That's like cereal or bread, isn't it? I know, because last year in school, we got to grind the grain, and make bread in school.

Granny: Good for you! Have you ever done that, boys and girls?

Jody: Granny, why do we need all those kinds of foods? Granny: Well, you need all of them, because they work together to give your body energy and to make your body grow. That's why we call them the magic foods. They work like magic for you.

Jody: Magic? Wow! They musta been in that magic food pot. Weren't they? Huh?

Granny: That's right, the healthy food materials and substances are the good things in our foods that give us energy and make us want to run and play. Everytime you move your finger, or your foot it takes energy, and when you run fast, it takes lots more energy. It's like putting gas in your family car to make its motor run. (Pats Jody's stomach) 
When you don't put food in there, your motor can't run and you're tired, so it's important to eat your meals, isn't it, boys and girls?

Jody: Gosh, Granny Goody, I didn't know how important food was, or that skipping a meal would make me feel so tired.

Granny: Why do you suppose Jody didn't know that? Shall we look for my magic food pot now?

Jody: Yes! (Excitedly)

Granny: It's right behind you. (Points at shelf)

Jody: But that's just a shelf.

Granny: It may look like a shelf, but it has the same healthy foods that were in the magic food pot.

Jody: What's so special about those foods, Granny?

Granny: What's so special Jody, is that they have substances in them which we call nutrients. Those nutrients have names of good things which our body needs like proteins, carbohydrates, fats, and vitamins. Jody: I know what vitamins are! Granny: Good, you'll learn what all the others are too, but right now let's choose one from each of the four magic food groups, the ones you need to work together to give you energy.

Jody: Great! I'm getting hungry!

Granny: How about some breakfast?

Jody: Sounds grood: 
Granny: (She brings him breakfast) Tell you what, while you're eating I'll get a sack, and we'll fix a good lunch for you too. (Gets sack) Now, you help me. First let's look for something from the magic food pot.

Jody: I like cheese and peanuts.

Granny: That's a good choice, they have protein in them. Jody: And I like apples, and bananas.

Granny: That will give you some carbohydrates and vitamins. How about a sandwich? This one is roast beef.

Jody: Hmm. It has lettuce, and butter, and mayonnaise, and bread. Do I really need a sandwich?

Granny: Yes, Jody. The bread will give you something made from grains and the mayonnaise and butter will give you some fat which you need, and the beef will give you some more proteins.

Jody: Did we forget anything?

Granny: There are lots of good foods, Jody, but I think these will give you enough energy for school today.

Jody: What about milk?

Granny: You have cheese, that's made from milk, but you're right, you need milk, too. Run along, now.

Jody: Bye, bye.

Granny: (To audience) I do hope Jody got the message, don't you, boys and girls? And I hope you did 
too. You need healthy foods, and you need to eat breakfast, lunch, and dinner every day. You need healthy foods for energy, so your bodies will grow strong.

\section{Epilogue}

\section{After School (Sign appears)}

Jody: (Pops head in) Granny, I ate all my lunch and I've got--what did you call it when our bodies are feeling good?

Granny: Energy--you've got energy!

Jody: I've got energy! I feel good now. I'll bet I could mun all the way to school tomorrow and not be late anymore. I think I'll tell my friends about the magic foods and ENERGY. Bye, bye. .

Granny: Oh, isn't that nice! I bet Jody won't skip meals anymore, and don't you either! (Wave) Bye, bye! 


\section{SCRIPT FOR DRAMATIC STORYTELIING}

Directions: Place two chairs facing the children. Granny will tell the story. Use an old lady voice for Granny. For Jody's words use a childlike voice. Gestures, postures, and expressions are in parentheses.

(Speaking like old lady) Hello, boys and girls. My name is Granny Goody, and I'm here to tell you a story about a boy who is just about your age. His name is Jody. One morning while I was cleaning my kitchen, (pantomime wiping a table) I heard a knock (knock) at my door, so I slowly shuffled over to the door. There stood my grandson, Jody, with his head hanging down, looking all droopy. (Droop shoulders and hang head) I said, (surprised) "Why Jody, what are you doing here?" He didn't answer, he just stood there. So I said, "Did someone hurt you?"

"No." (Shaking head)

I knew something was the matter, so I said, "Come now, tell Granny why you're here, and what the problem is." "I'm just tired." "Tired, at nine o'clock in the morning? (Surprised) Nine o'clock in the morning! Hmm. Why aren't you in school? Shouldn't Jody be in school boys and girls?" Jody slowly replied, "Well, I was on my way, but I saw your house and I was tired, so I thought I'd stop and 
rest a minute."

"Rest? You should have lots of pep and energy right after breakfast, shouldn't he boys and girls, or didn't you eat your breakfast?"

Jody was getting a little nervous so he said, "Well, a, a, (hurriedly) I, I just wasn't hungry."

(Gasp) "Isn't that terrible boys and girls? Jody skipped breakfast. No wonder he's so droopy and tired. Boys and girls need to eat a good breakfast. All of you know that, don't you?" (Pause for audience response) "See Jody, all of the boys and girls know that they need to eat a good breakfast."

"Aw shucks, what's so special about breakfast?" "What's so special about breakfast? You sit right down (pat chair with hand) and Granny!ll tell you what's so special."

(Pouting) "I'd rather hear a story." (To boys and girls) Wouldn't you rather hear a story boys and girls?" "You would?" "Well, then I'll tell you a story. I know, I'll tell you about the Land of Energy. A long time ago in the Land of Energy, there were boys and girls who could run, and jump, and play all day and never get tired." "Never?" (Disbelievingly)

"At night when their parents tucked them into bed, the children were still full of energy, and would beg for just one more story. Mothers and dads couldn't figure out 
why the children had so much energy and would say to each other, (change voice) 'Tommy should be tired. He's played so hard today, but he's still so full of energy.' Well, the children had a secret." When Jody heard the word secret, he got all excited.

(Move around excitedly) "Secret, he said, did you say a secret?" "Did she say a secret?" (To boys and girls) "Yes, a secret. The children had found a magic food pot just full of healthy foods, and every morning, you know what they'd do? They'd eat out of this magic food pot. Then one day, a bad old wizard came along and stole the magic food pot, and hid it where the boys and girls couldn't find it, and so they had no healthy foods." Well, Jody could hardly believe this, so he said, "Did he really? What a mean old wizard! Wasn't he a mean old wizard, boys and girls?"

I agreed with Jody and so I said, "He sure was, and without healthy foods everyday, the boys and girls (droop) soon became very tired. They couldn'trun, or jump, and they just wanted to sit around all day."

"Just like me; huh Granny?"

"Right, just like you Jody, but all wasn't lost. What do you suppose happened?"

"What? What?"

"One day a farmer was digging around, and he found an old iron pot. He looked at it, and it didn't look like 
much, so he just threw it over the fence in his field, and what do you think happened?"

\section{"What?" (Excitedly)}

"Suddenly, a magic tree popped right out of the ground. It had all sorts of good foods on it. No one had ever seen anything. like it before, and when people ate food off that tree, they were filled with energy. But they were all puzzled, until an old grampa remembered a magic food pot that he had eaten out of every morning when he was a little boy."

With that Jody jumped up excitedly and said, "I know, I know, that iron pot must have been the magic food pot, huh Granny. I wish. I could find a magic food pot. Maybe then I wouldn't be so tired."

I looked at Jody and said, "I think you can. There's a magic food pot in my kitchen, and in your kitchen, and in yours, too, boys and girls. It's your refrigerator and your cupboard." "They probably have all kinds of healthy foods in them. But do you know what healthy foods are?" Jody said, "Sure, apples, and milk, and" (pause) and a, a, "Iooks like Jody's stuck boys and girls. Do you think you can help him out? What are some healthy foods, boys and girls? (Children's responses acknowledged) "That's right, everyday you need fruits and vegetables, meat or peanut butter, or fish, milk; or something made out of milk, and bread or cereal." 
Well, Jody was still a little doubtful, so he said, "Granny, why do we need all those kinds of foods?"

And I told him, "You need all of them to work together to give your body energy and to make your body grow. That's why we call them the magic foods. They work like magic for you."

When Jody heard the word magic, he got all excited and shouted, "Magic, Wow!"

And I said, "That's right, magic! Everytime you move your finger or your foot it takes energy, and when you run fast, it takes lots more energy. It's like putting gas in your family car to make its motor run. When you don't put good food in there, (points to stomach) your motor can't run and you're tired, so it's important to eat your meals. Isn't it boys and girls?"

Well, when Jody heard that he said, "Gosh, Granny Goody, I didn't know how important food was, or that skipping a meal would make me feel so tired."

After all that talk Jody finally said, "Granny I'm getting hungry!"

So I said to him, "How about some breakfast? Here's a bowl of cereal, some strawberries, and a glass of milk. That's something from the fruit group, the cereal group and the milk group."

Jody looked at them and said, "Oh, they look so good." 
And I said, "While you're eating breakfast, I'm going to pack you a Iunch too. Maybe if you start eating breakfast, lunch, and dinner you'll get some energy. Why don't you help me choose some foods from the four food groups for your lunch."

So Jody said, "Okay," and looked in my refrigerator and in my cupboard. He found cheese for the milk group, an apple for the fruit group and vegetable group, and I made him a big, juicy, roast beef sandwich with lettuce and butter and mayonnaise on it, so he'd have something from the meat group and bread group. He finished his breakfast, grabbed his lunch sack and was off to school.

As I watched him go, I said to myself, "I do hope Jody got the message, and I hope you did too boys and girls. You need to eat breakfast everyday. You need healthy foods for energy and so your bodies will grow and you'll be strong and healthy."

I finished cleaning my kitchen, had my lunch, took a nap, and at 2:45 in ran Jody just bursting with energy. He grabbed me and gave me a great big hug as he shouted, "Granny, I've got energy! I feel so good now. I think I'll tell all of my friends about the magic foods and ENERGY. See you later Granny. Bye, bye!"

"Isn't that great boys and girls, I'll bet Jody won't skip meals anymore, and don't you either." (Wave) Bye! Bye! 
APPENDIX C

PHOTOGRAPHS OF PUPPETS AND PROPS 


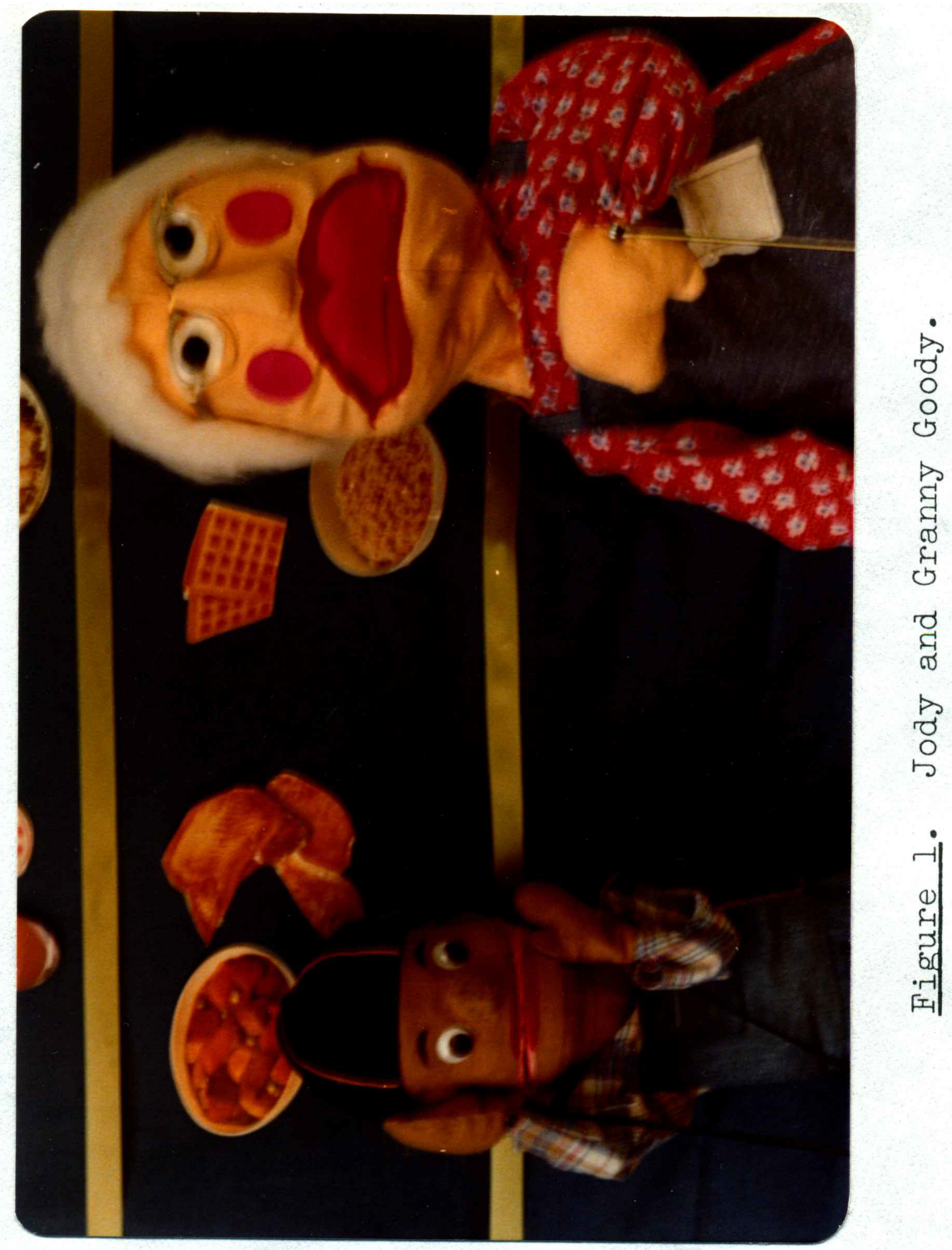




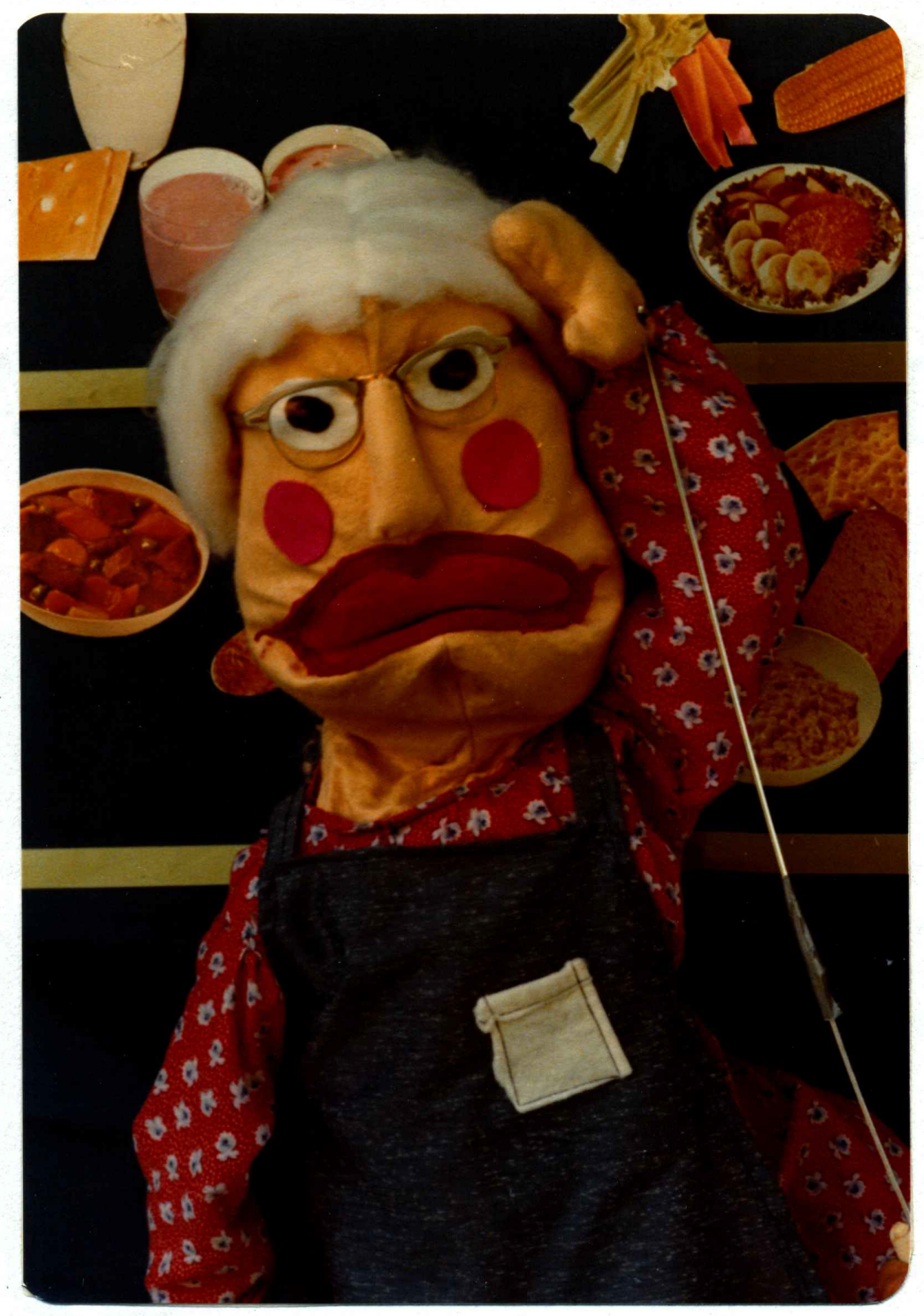

Figure 2. Granny Goody. 


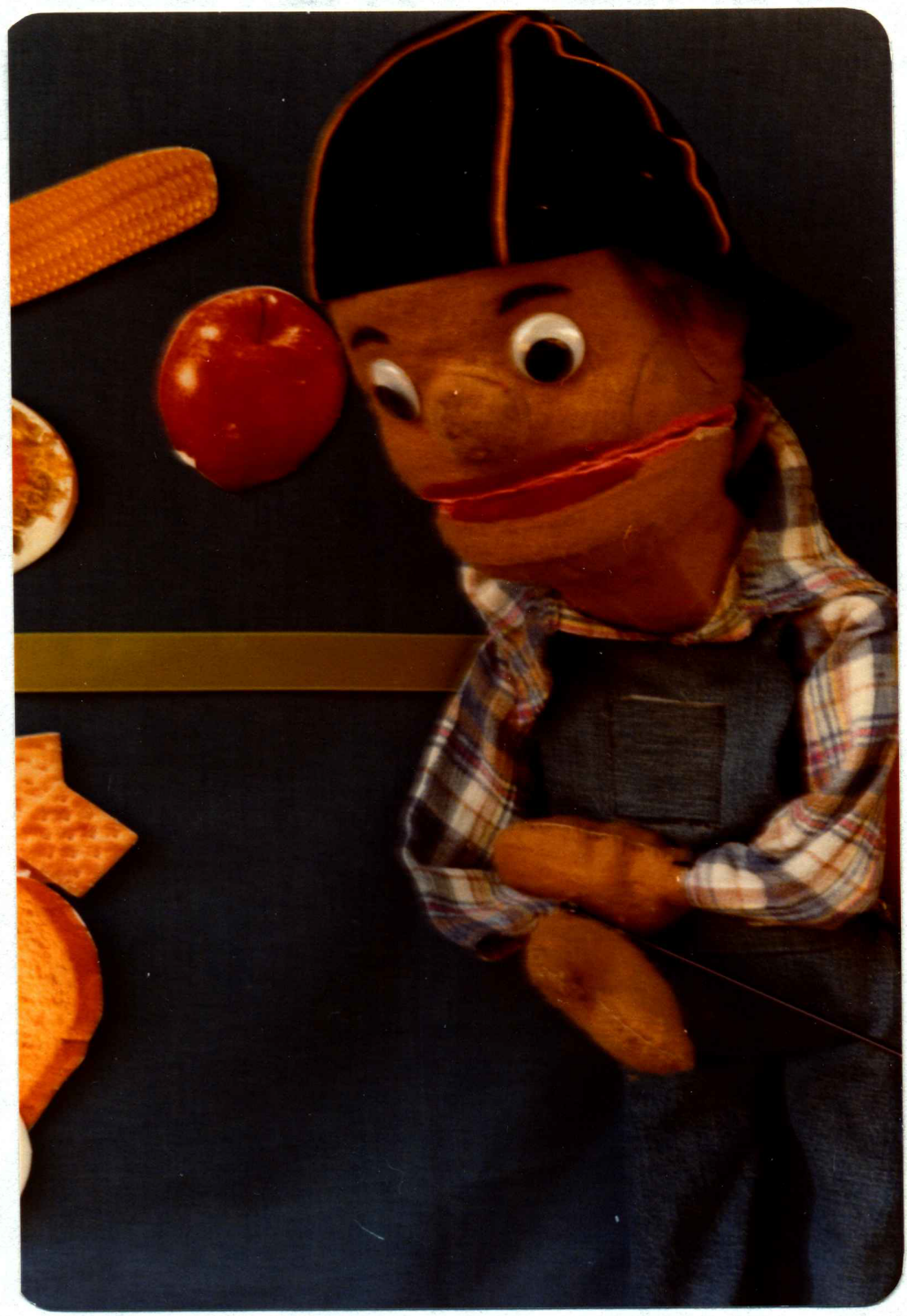

Figure 3. Jody. 


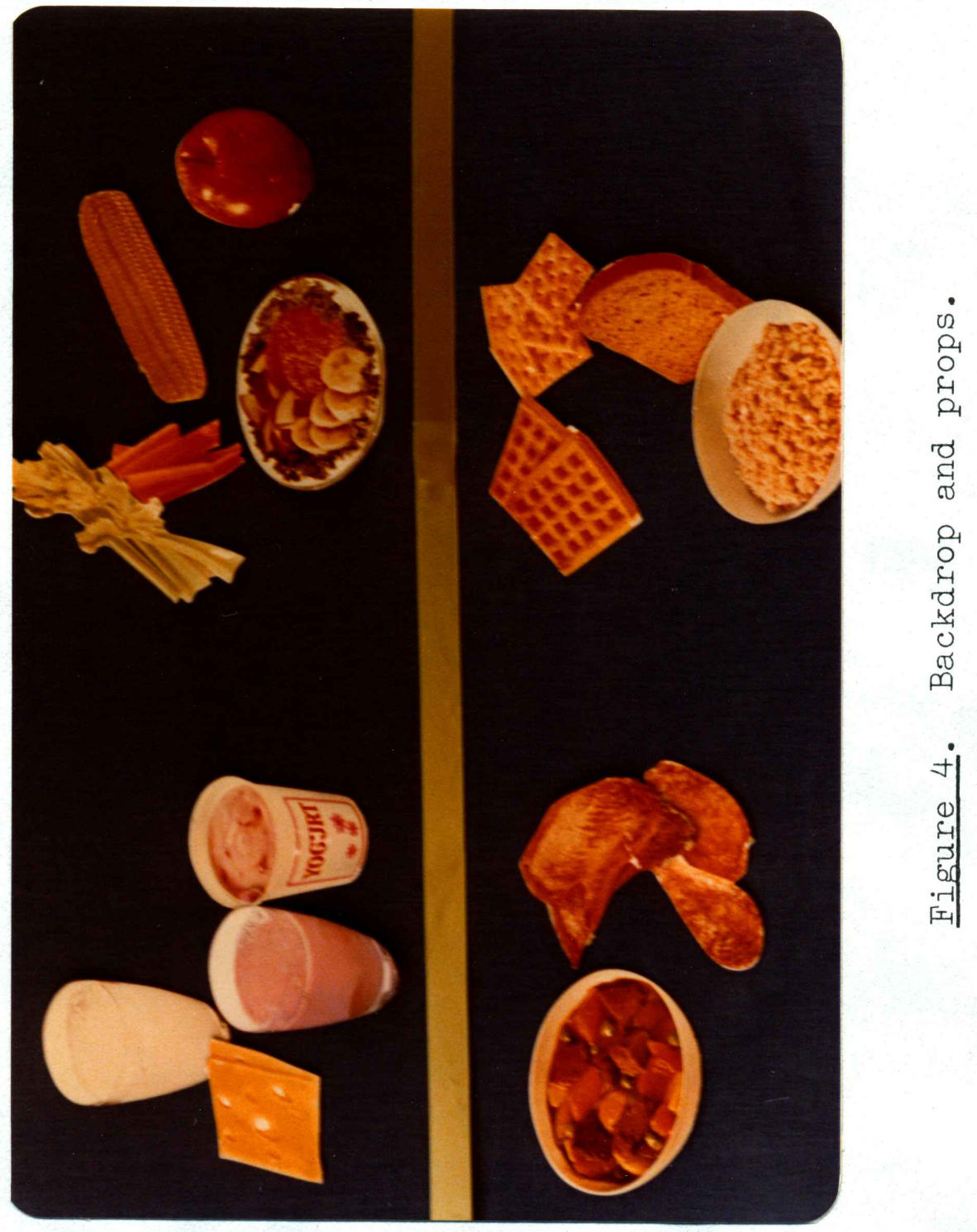




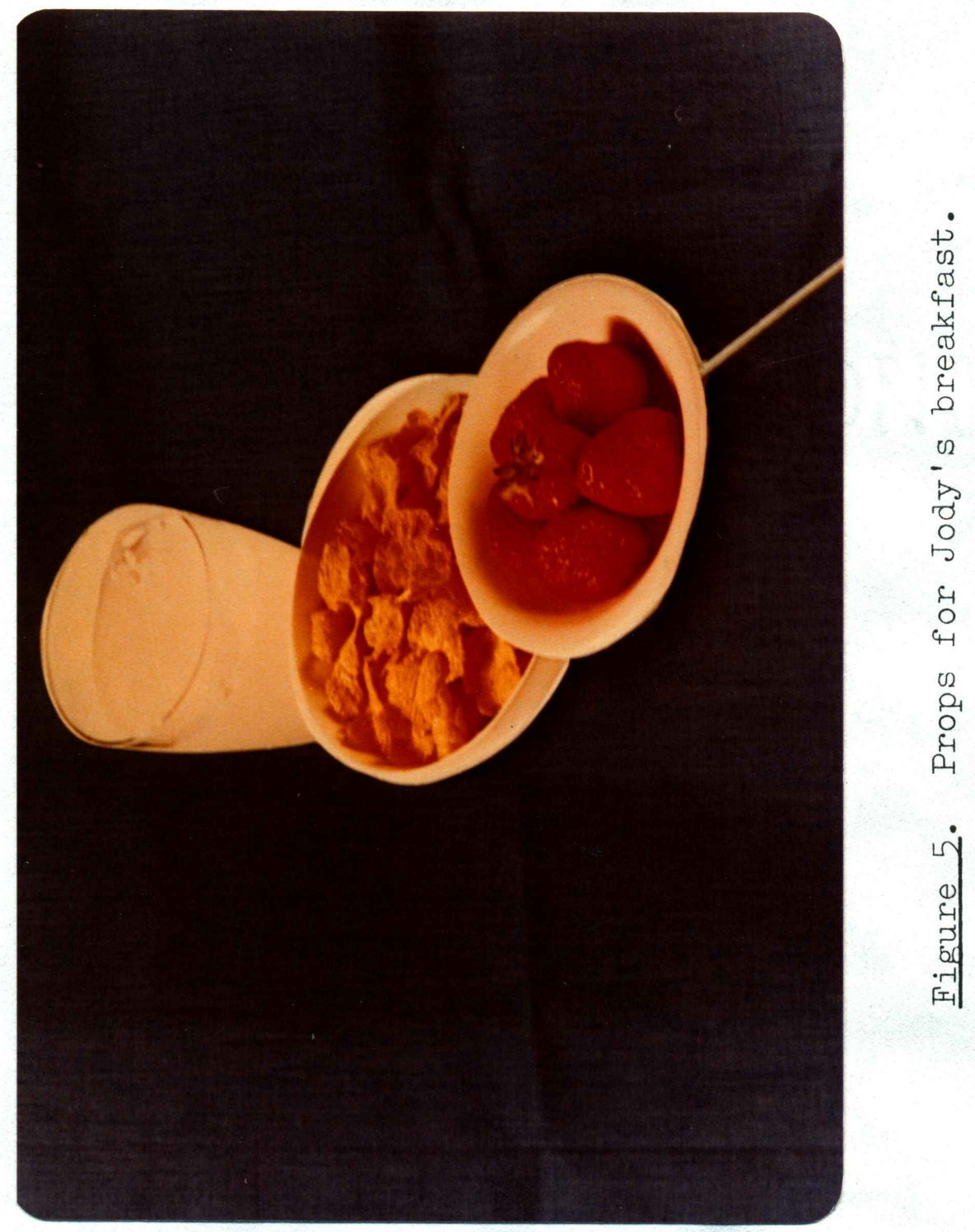




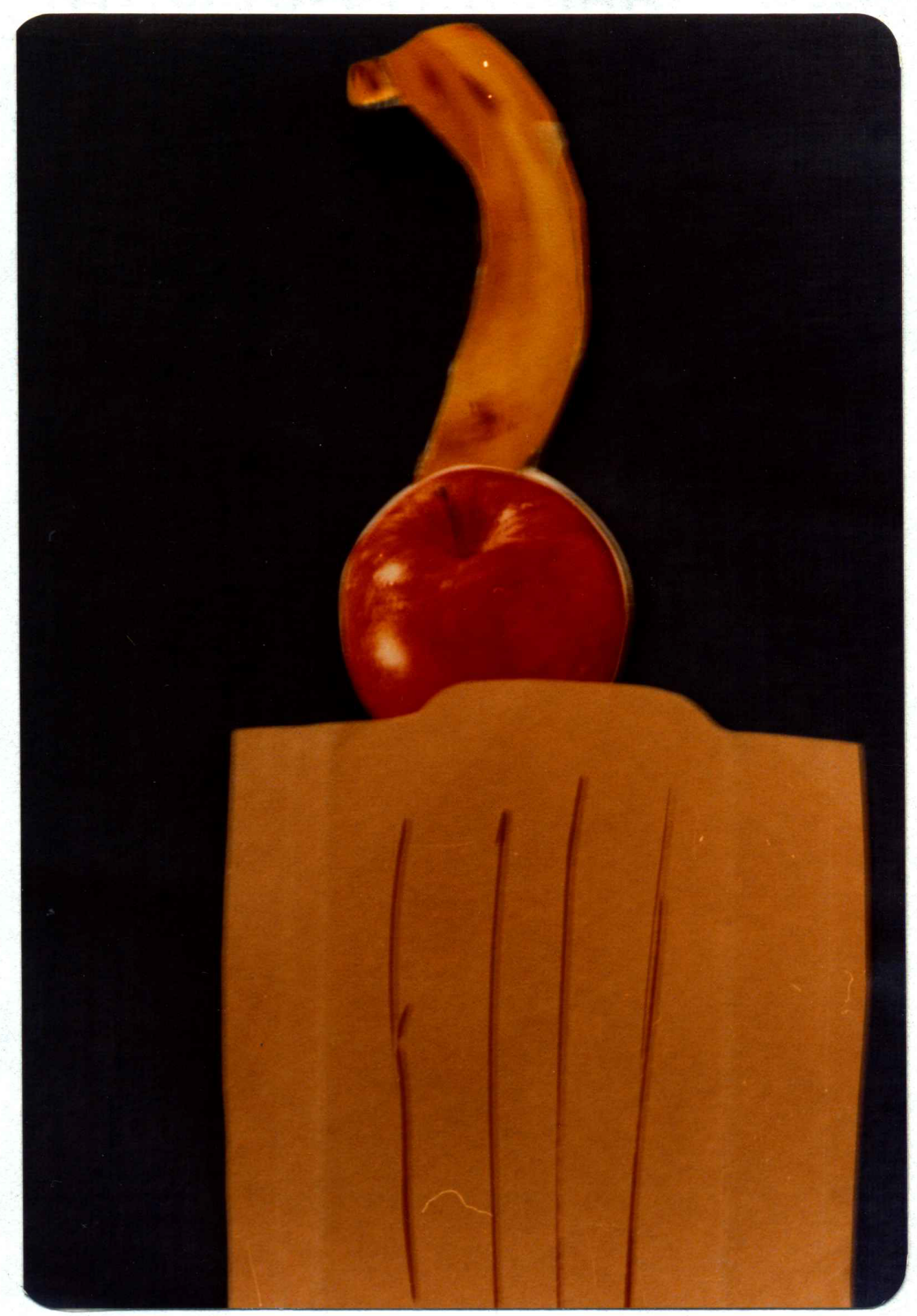

Figure 6 . The lunch sack props. 


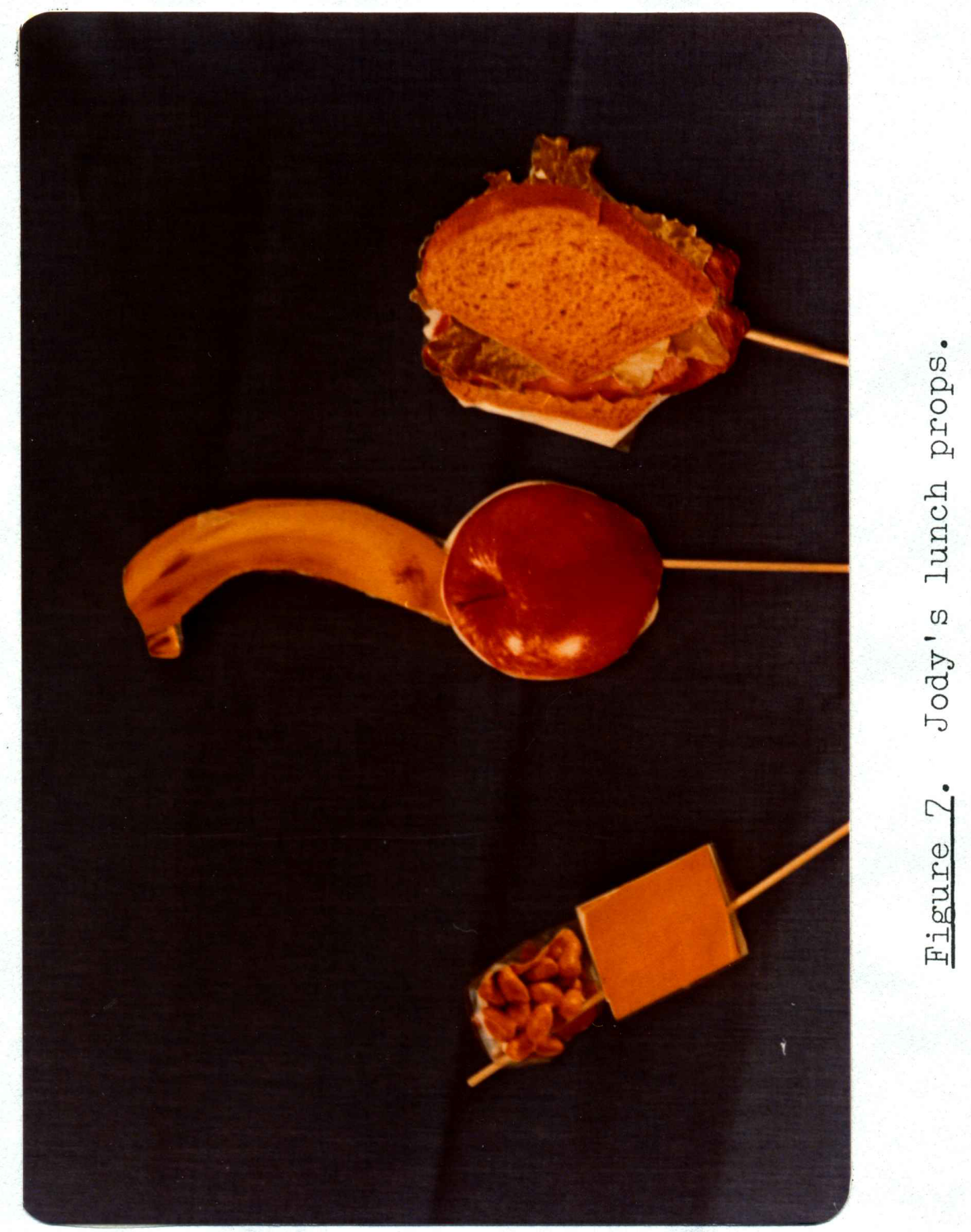


APPENDIX D

LIST OF ALL PRETEST, POSTTEST, AND CHANGE SCORES 
LIST OF ALI PRETEST, POSTTEST,

AND CHANGE SCORES

\section{Control Group:}

Pretest scores

42

30

45

55

52

55

49

70

37

85

61

79

73

55

55

67

73

79

34

52

76

43

79

79

73

55
Posttest scores

82

66

79

85

79

82

73

91

52

100

76

91

82

64

64

76

82

85

40

58

82

49

85

85

79

58
Change scores

40

36

34

30

27

27

24

21

15

15

15

12

9

9

9

9

9

6

6

6

6

6

6

6

6

3 
Pretest scores

82

46

85

79

85

79

91

E4

49

97

97

88

67

18

31

91
Posttest scores

85

49

85

79

85

79

91

64

46

94

91

82

61

9

15

75
Change scores

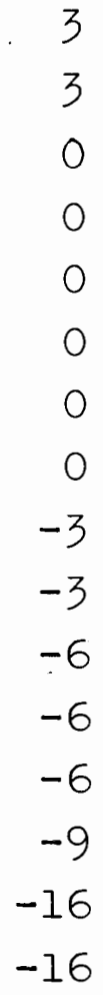

Experimental Group:

30

40

45

35

50

25

40

48

55

49

53

55

52

64

60
100

97

100

90

98

68

82

88

94

85

88

88

85

94

90
70

57

55

55

48

43

42

40

39

36

35

33

33

30

30 
Pretest scores

70

55

55

49

63

64

67

70

67

64

64

58

70

64

61

67

73

64

64

64

67

73

73

79

67

76

58

76

82

55

79

49

58
Posttest scores

100

85

85

76

89

91

94

97

91

88

88

82

94

88

85

91

97

88

85

85

88

94

94

90

88

97

79

94

100

73

97

67

76
Change scores

30

30

30

27

27

27

27

27

24

24

24

24

24

24

24

24

24

24

21

21

21

21

21

21

21

21

21

18

18

18

18

18

18 
Pretest scores

70

76

73

70

70

73

61

70

85

79

70

82

75

76

73

73

73

76

76

76

76

76

67

67

85

85

88

79

85

82

88

85

85
Posttest scores

98

94

91

88

88

88

76

85

100

94

85

97

90

91

85

85

85

88

88

88

88

88

79

79

97

97

100

91

97

94

100

94

94
Change scores

18

18

18

18

18

15

15

15

15

15

15

15

15

15

12

12

12

12

12

12

12

12

12

12

12

12

12

12

12

12

12

9

9 
Pretest scores

73

82

85

85

73

85

88

79

67

85

73

79

91

82

91

82

85

79

82

91

82

82

94

82

82

91

91

91

79

79
Posttest scores

82

91

94

94

82

94

97

88

76

94

82

88

97

88

97

88

91

85

88

97

88

88

100

88

85

94

94

94

82

82
Change scores

9

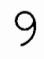

9

9

9

9

9

9

9

9

9

9

6

6

6

6

6

6

6

6

6

6

6

6

3

3

3

3

3

3 